\title{
小江断裂带系统深部物质运移机制及孕震环境: 来自大地电磁阵列数据的证据
}

余年 ${ }^{1,2^{*}}$, 王绪本 ${ }^{3 \dagger}$, 李德伟 ${ }^{3}$, 李墓金 ${ }^{4}$ 王恩慈 ${ }^{1}, 孔^{⿱ 亠 乂}$ 新 $^{2}$, 李天阳 ${ }^{2}$

1. 重庆大学电气工程学院, 重庆 $400044 ;$

2. 煤矿灾害动力学与控制国家重点实验室, 重庆 400044;

3. 成都理工大学地球物理学院, 成都 610059 ;

4. 中国科学院地质与地球物理研究所, 北京 100029

* 通讯作者, E-mail: yunian@126.com

†通讯作者, E-mail: wxb@cdut.edu.cn

收稿日期: 2021-12-13; 收修改稿日期: 2022-02-17; 接受日期: 2022-03-01; 网络版发表日期: 2022-04-18

国家自然科学基金项目(批准号: 91755215、42074081、42104071)和重庆市自然科学杰出青年基金项目(编号: cstc2021jcyj-jqX0018)资助

摘要位于青藏高原东南边界的小江断裂带系统构造运动强烈, 是研究和检验高原物质运移模式及其构造响应 的理想场所. 研究基于横跨该断裂系统的宽频大地电磁和长周期大地电磁阵列观测数据, 通过三维反演构建了岩 石圈三维精细电性结构模型. 模型显示, 中上地壳走滑断裂之间存在三条明显的南北向高阻分界线, 可能为峨眉 山大火成岩省被新生代地壳构造活动破坏和改造的残留; 中下地壳呈现显著的低阻特征, 并向下延伸至上地幔深 度.分析表明, 中上地壳低阻体可以用含盐水流体和高导矿物质(如石墨、金属硫化物)共同来解释, 而视无水矿物 质中的结构水和部分熔融是下地壳和上地幔低阻可能的成因. 基于区域内地震活动和电性结构的空间分布特征, 可将小江地区地震分为构造地震、地表无活动断裂地震和无明显分布规律地震三类，主要由构造活动、流体运 移和应力场调整等因素协同作用影响。研究认为地震与深部流体之间存在相互促进的关系: 一方面，流体的存在 可显著降低断裂带内的摩擦力, 促进断裂运动, 从而诱发地震; 另一方面, 地震活动和长期的走滑/剪切活动可产 生热量并增强流体连通性, 从而降低地壳强度, 促进流体的运移. 基于成像结果, 认为小江断裂带系统现今深部构 造活动呈现为中上地壳沿走滑断裂刚性挤出、中下地壳以地壳通道流方式塑性蠕动、上地幔存在上涌的复杂模 式. 结合前人研究成果, 推测来自青藏高原的壳内弱物质流经川滇地块时受到峨眉山古地幔柱活动改造的岩石圈 和华南地块阻挡, 沿小江断裂带系统转向西南方向, 穿过红河断裂带后进入印支地块.

关键词 小江断裂带, 大地电磁测深, 桑震环境, 峨眉山古地幔柱, 地壳流

中文引用格式: 余年, 王绪本, 李德伟, 李傘, 王恩慈, 孔文新, 李天阳. 2022. 小江断裂带系统深部物质运移机制及孕震环境: 来自大地电磁阵列数据的证据. 中 国科学: 地球科学, 52(6): 1132-1150, doi: 10.1360/SSTe-2021-0381

英文引用格式: Yu N, Wang X, Li D, Li X, Wang E, Kong W, Li T. 2022. The mechanism of deep material transport and seismogenic environment of the Xiaojiang fault system revealed by 3-D magnetotelluric study. Science China Earth Sciences, 65(6): 1128-1145, https://doi.org/10.1007/s11430-021-9914-3 


\section{1 引言}

新生代以来，印度板块对欧亚大陆的碰撞挤压造 成青藏高原的隆升，形成了当今的青藏高原，地壳和 上地幔物质的运移是影响高原构造变形的重要因素之 一(Tapponnier等, 2001; Royden等, 2008; 高原等, 2020). 高原物质的侧向逃逸是调节高原物质平衡的重 要方式, 目前地学界有多种构造变形模式来解释其运 动机制, 其中最为重要的两种观点: 一是“刚性块体挤 出模型”, 其认为青藏高原刚性岩石圈被多条大型走滑 断裂分隔为数个较小刚性块体，在印度板块的推挤作 用下沿边界断裂被挤出(Molnar和Tapponnier，1975; Tapponnier等，1982，2001); 二是“地壳流模型”，认为 青藏高原中部岩石圈物质在重力均衡的作用下以塑性 蠕变的方式，通过中下地壳的低黏度通道运移到青藏 高原东南缘(Royden等，1997; Clark和Royden，2000; Beaumont等，2001)，并受到大型走滑剪切带的控制 (Bai等, 2010; Bao等, 2015). 这两种端元模型对青藏高 原的地质演化过程认识完全不同，前者假设这些走滑 断裂是贯穿整个岩石圈，并存在较高的滑动速率和较 大的水平位移，而后者认为走滑断裂为地壳构造，滑 动速率有限, 物质均衡主要依靠中下地壳的黏性变形 来调节. 因此，对青藏高原东南缘走滑断裂深部结构 开展深入研究有助于验证这两种端元模型的正确性.

作为青藏高原的东南边界, 小江断裂带位于南北 地震带南段，具有强烈的新构造活动，在青藏高原物 质东南逃逸过程中发挥了重要作用(图1). GPS观测结 果表明青藏高原东南缘地壳整体正围绕喜马拉雅东构 造结做顺时针旋转(Chen等, 2000; Zhang等, 2004; Shen 等，2005)，造成这种运动的深部驱动机制可能是青藏 高原深部弱物质的运移. 大量的深部地球物理观测结 果(Bai等, 2010; Zhao等, 2013; Chen等, 2014; Bao等, 2015; Qiao等，2018)揭示在青藏高原东南缘存在两个 低速、高导、高熔融比的壳内弱物质通道，其中东侧 一支大致沿着鲜水河-小江断裂带分布. 然而，不同观 测揭示的弱物质通道空间位置和范围存在差异, 如Bao 等(2015)结果显示通道东支范围覆盖整个小江断裂带, 而Bai等(2010)和Qiao等(2018)结果却显示通道仅在小 江断裂带西侧. 此外, 还有不少青藏高原东南缘地震观 测表明小江断裂带附近低速高导异常不仅存在于地壳 结构中, 而且也存在于上地幔, 这意味着该地区的地幔
可能是高温且软弱的(Li等, 2008; Hu等, 2015; Huang 等, 2015; Yang等, 2015; Li等, 2019; Yu等, 2020). 与此 同时, 小江断裂带是一个地震构造极为复杂的区域, 地 震以频度低、强度高著称, 地震的破裂已完全覆盖了 整个断裂带, 被认为是云南地区最强烈的地震发生带 (闻学泽等, 2011), 小江地区深部孕震环境值得关注和 研究. 在前期深部地球物理研究中, 多数是将小江断裂 带作为讨论的部分内容, 对其研究有待进一步深入; 特 别是在电性结构研究方面, 缺少针对小江断裂带开展 的三维探测研究. 因此, 为了解小江断裂带系统可能 的地壳和地幔物质流动及孕震环境, 迫切需要对该地 区岩石圈电性结构进行更为精细的探讨.

大地电磁法是一种对地球深部结构进行成像的频 率域电磁法，已经广泛应用于断层相关结构和构造过 程研究(Hoffmann-Rothe等，2004; Unsworth等，2005; Ritter等, 2005; Becken等, 2011). 大地电磁对流体等低 阻异常较为敏感, 已经成为研究古代板块和现代边界 的有效工具(Jones, 1993; Unsworth和Bedrosian, 2004a). 在本项研究中, 我们对研究区宽频带大地电磁 和长周期大地电磁数据进行反演, 获得小江断裂带系 统岩石圈的首个三维电阻率结构模型, 该模型揭示了 研究区地壳和上地幔结构的一些新细节，为小江断裂 带系统及青藏高原东缘的深部物质运移和孕震环境分 析提供了新的见解.

\section{2 研究区地质与地球物理研究现状}

\section{1 地质构造背景}

青藏高原东南缘区域以金沙江-红河断裂、安宁 河-则木河-小江断裂、丽江-小金河断裂为界，可以划 分为松潘-甘孜地块、川滇地块、华南地块和印支地 块(图1). 小江断裂带位于华南地块与川滇地块的接触 部位, 向北与鲜水河断裂、龙门山断裂相连, 向南延伸 至红河断裂，是区域内的一条大型活动断裂和强震发 生带(Zhang，2013). 小江断裂带系统由南北向平行分 布的绿汁江断裂、易门断裂、普渡河断裂和小江断裂 等数条分支断裂构成，东西展布约 $200 \mathrm{~km}$. GPS观测资 料显示青藏高原东南缘顺时针旋转的地壳应变主要集 中在小江断裂带等边界断裂上(Shen等, 2005; Wang和 Shen, 2020).

研究区内广泛分布中生代-古生代沉积岩, 在绿汁 

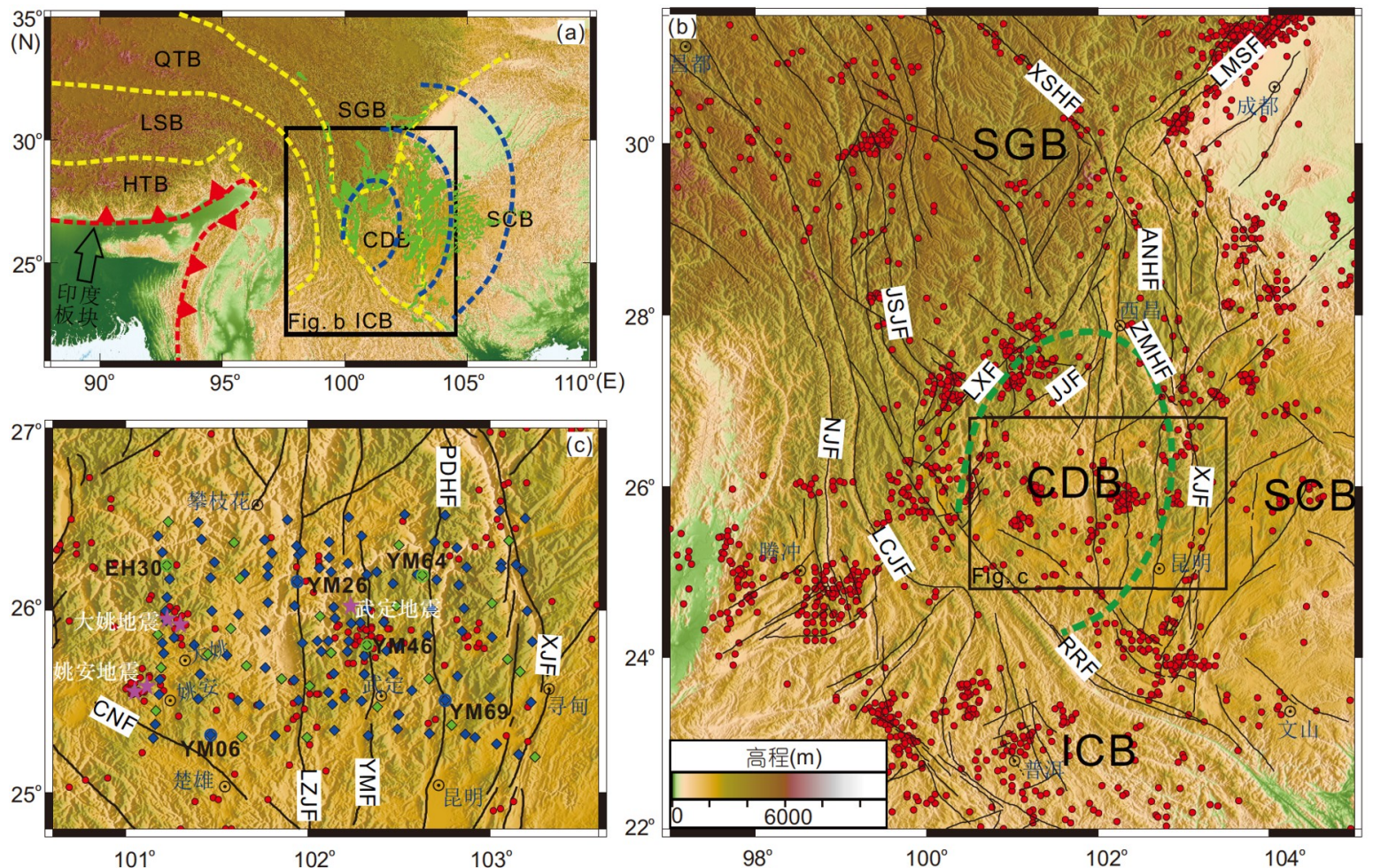

图 1 研究区构造背景与大地电磁测点分布

(a) 青藏高原东缘及邻区构造图, 黄色虚线为主要地块之间的分界线, 蓝色虚线为推断的峨眉山火成岩省内带、中带和外带(Xu等, 2004), 绿色 区域为峨眉山玄武岩分布. CDB: 川滇地块; QTB: 㒸塘地块; SGB: 松潘-甘孜地块; LSB: 拉萨地块; HTB: 喜马拉雅逆冲构造带; SCB: 华南地 块; ICB: 印支地块. (b) 青藏高原东缘断裂构造与地震分布, 绿色虚线为推断的峨眉山火成岩省内带, 红色圆圈表示震中位置. XSHF: 鲜水河断 裂; LMSF: 龙门山断裂; JSJF: 金沙江断裂; NJF: 怒江断裂; LCJF: 澜沧江断裂; RRF: 红河断裂; LXF: 丽江-小金河断裂; JJF: 金河-菁河断裂; ANHF: 安宁河断裂; ZMHF: 则木河断裂; XJF: 小江断裂带. 红色圆圈为 1970 年以来 $>M_{\mathrm{S}} 3.0$ 地震分布(数据来源: 国家地震科学数据中心). (c) 研究区大地电磁测点分布, 蓝色菱形为宽频大地电磁测点, 绿色菱形为宽频与长周期大地电磁共点测点. YM06、YM26、YM69为宽频测点 代表, EH30、YM46、YM64为长周期测点代表. LZJF: 绿汁江断裂; YMF: 易门断裂; PDHF: 普渡河断裂; CNF: 楚雄-南华断裂

江断裂、易门断裂附近分布有新近系-古近系地层, 岩 浆岩以中生代-古生代为主, 主要沿着普渡河断裂和小 江断裂之间呈南北向分布(吴熙彦等, 2018). 绿汁江断 裂为小江断裂带系统最西侧断裂，以左行剪切走滑为 主，晚第四纪平均水平滑动速率为 $1 \sim 2.0 \mathrm{~mm} \mathrm{a}^{-1}$ (卢海 峰等，2008). 易门断裂是一条多期活动断裂，印支期 呈现右旋张扭性, 燕山期为左旋压扭性, 新构造运动显 示左旋压扭性特征(俞维贤等, 2004), 于1995年10月24 日发生武定有记录以来最大地震 $\left(M_{\mathrm{S}} 6.5\right)$. 普渡河断裂 主要活动时代为上新世, 在第四纪显示左旋剪切特征, 左旋位移速率为 $0.9 \sim 2.0 \mathrm{~mm} \mathrm{a}^{-1}$ (陈立春等, 2013). 小江 断裂带从中晚更新世以来左旋走滑运动明显, 最大运 动速率 $>10.0 \mathrm{~mm} \mathrm{a}^{-1}$, 最南段降低至约 $3.5 \mathrm{~mm} \mathrm{a}^{-1}$ (徐锡 伟等, 2003). 较高的滑动速率使得小江断裂带成为云
南地区最强烈的地震带之一, 500 年以来已发生 16 次 $>6.0$ 级的地震(闻学泽等, 2011).

\section{2 地球物理研究现状}

前人在小江断裂带及邻区开展了大量地球物理研 究工作. 重力研究发现楚雄-南华断裂带至普渡河断裂 带之间存在一个较大范围的重力异常, 推测与二叠系 峨眉山玄武岩出露有关, 认为川滇地块与华南地块的 密度边界并非小江断裂带, 而是普渡河断裂带(石磊 等, 2015).

“地壳流模型”很好地解释了青藏高原东南缘剧烈 的地壳物质挤压却没有很大的地表变形缩短的现象 (Royden等，1997; Clark和Royden, 2000)，同时也得到 多种深部地球物理结果的支持，如中下地壳的低速带 
(Yao等, 2008; Liu等, 2014; Chen等, 2014; Bao等, 2015; Li等，2016; $\mathrm{Fu}$ 等，2017; Qiao等，2018; 张智奇等, 2020)、低电阻率(Bai等, 2010; Ye等, 2018; Cheng等, 2019; Li等, 2019; Yu等, 2020)、高衰减(Zhao等, 2013) 等异常. 但这些研究在地壳通道流的空间分布上认识 不一致, 有观测结果显示小江断裂带东西两侧均发育 有低速带(Yao等，2008；Bao等，2015；Qiao等，2018; 张智奇等, 2020), 也有研究显示低速带或低阻带主要 发育在小江断裂带西侧(Bai等, 2010; Fu等, 2017; Li等, 2019).

与此同时，区域地震层析成像成果显示小江断裂 带附近上地幔存在明显的低速异常(吴建平等, 2013; Huang等, 2015; Lei等, 2019), 认为小江断裂带中部上 地幔低速异常体与地壳低速体相连, 结合研究区的高 热流值(平均值达到 $85 \mathrm{~mW} \mathrm{~m}^{-2}$ ), 推测地壳低速异常与 上地幔之间热交换有关. 小江断裂带系统岩石圈地球 物理异常与深部物质运移的关系有待进一步研究和 探讨.

在电性结构研究方面, 目前为止有四条大地电磁 剖面通过小江断裂带. Bai等(2010)通过青藏高原东南 缘布置的四条大地电磁剖面推测存在地壳流沿小江断 裂带西侧通过研究区, 但由于剖面之间间隔较大, 无法 给出确切的证据. 李再等(2014)在云南南部实施的孟 连-罗平的北东向大地电磁剖面穿过小江断裂, 显示小 江断裂深部有大规模低阻体发育, 认为强烈的地壳活 动与活动断裂的发育及深部低阻热物质的流动是地震 多发的诱因. Li等(2019)通过两条东西向穿过小江断裂 带的大地电磁剖面三维反演研究, 认为小江断裂带受 地壳流和地幔流上涌的综合影响. 前期大地电磁研究 成果仅为剖面形式展开, 无法对小江断裂带系统复杂 的三维岩石圈形态进行完整探讨与分析. 本次研究是 第一次采用宽频和长周期大地电磁对小江断裂带系统 开展阵列式三维成像研究.

\section{3 数据和方法}

\section{1 数据采集和处理}

大地电磁测点面积性分布在 $101^{\circ} \sim 103.5^{\circ} \mathrm{E}, 25^{\circ} \sim$ $26.5^{\circ} \mathrm{N}$ 范围内, 共包含宽频大地电磁测点 138 个、长周 期大地电磁测点 28 个; 其中研究区最西侧 17 个宽频大 地电磁测点和 5 个长周期大地电磁测点为收集测点 $(\mathrm{Li}$
等, 2020), 研究区长周期测点位置均为宽频大地电磁 和长周期大地电磁共点采集. 宽频大地电磁野外数据 采集使用加拿大MTU-5A电磁法仪，观测时长均>20h; 长周期大地电磁测点观测采用乌克兰LEMI-417仪器, 观测时长均在 10 天以上. 由于城镇分布等原因, 测点分 布不均匀, 相邻测点点距在3 20km范围变化, 在武定 地震震中区测点更为密集(图1c).

宽频大地电磁数据处理采用开源程序包EMTF中 的Robust阻抗估算方法(Egbert， 1997), 对于部分测点 采用远参考技术(Gamble等, 1979)压制噪声干扰的影 响, 最终获得周期范围在 $320 \mathrm{~Hz} 2000$ s的响应数据. 长 周期大地电磁数据处采用PRC-MTMV 软件(Varentsov 等, 2003)计算得到周期范围10 10000s的阻抗数据. 对 同一测点上的宽频大地电磁和长周期大地电磁数据进 行拼接, 得到 $320 \mathrm{~Hz} 10000 \mathrm{~s}$ 的阻抗数据. 由于部分测 点、频段受到干扰, 视电阻率和阻抗相位曲线误差大, 因此我们将较差的频段删除, 以保证反演的稳定性和 可靠性.

典型测点的主阻抗视电阻率和相位曲线如图2所 示. EH30和YM60测点位于绿汁江断裂西侧, YM26测 点在绿汁江断裂附近, YM46测点在武定地震震中区, YM64和YM69测点位于普渡河断裂附近(图1c). EH30 和YM60测点的 $X Y$ 和 $Y X$ 分量中均显示低频电阻率有增 加的趋势, 表明绿汁江断裂西侧深部电阻率相对偏高. YM26测点两个视电阻率呈现明显的差异, $X Y$ 分量超 过 $10 \mathrm{~s}$ 为下降的趋势, 而 $Y X$ 分量却呈现为先上升再下 降的趋势, 说明其深部可能存在电阻率的分界面. 相 比之下，YM46、YM64和YM69测点的测深曲线超过 $10 \mathrm{~s}$ 后呈现明显的下降趋势, 其中YM64测点最小视电 阻率达到 $1.0 \Omega \cdot \mathrm{m}$, 这表明靠近普渡河断裂存在一个明 显的高导异常, 且可能达到上地幔深度.

\section{2 相位张量分析}

大地电磁测深通过反演建立地下深部电性结构, 合适的反演策略可以提高反演的效率与反演模型的可 靠性. 大地电磁阻抗张量分解技术可以对数据进行分 析, 定性反映研究区深部结构的维性特征和电性主轴 方向等信息. 在众多张量分解方法中, 相位张量分析 由于不受局部电场畸变造成的静位移影响, 亦不用考 虑构造维性的假设, 得到广泛的应用(Caldwell等, 2004). 相位张量 $(\boldsymbol{\Phi})$ 的计算公式如下: 

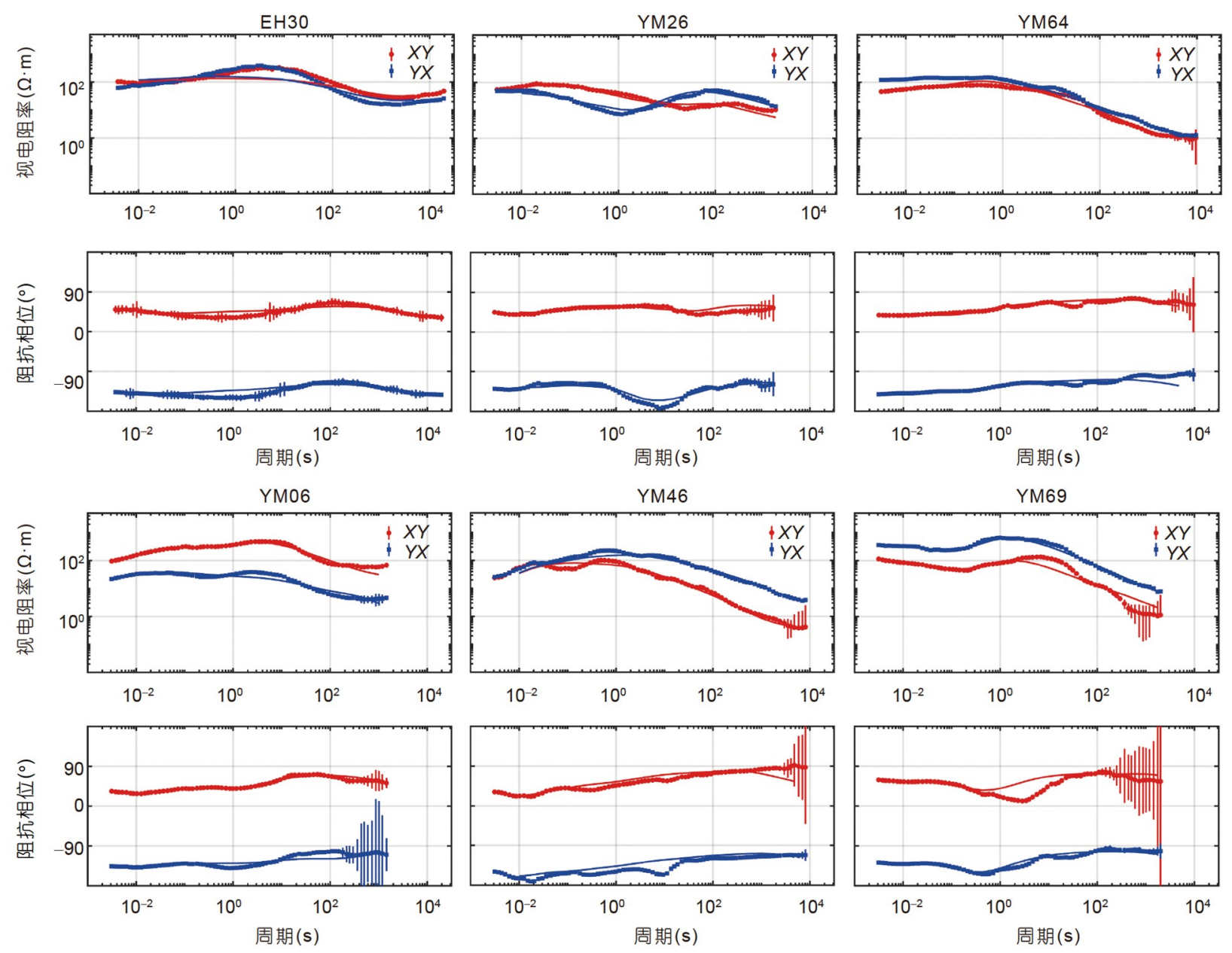

图 2 典型测点的主阻抗视电阻率和相位曲线

典型测点点位如图1c所示, 其中EH30、YM46和YM64为宽频和长周期大地电磁数据拼接后曲线, YM06、YM26和YM69为宽频大地电磁曲 线. 每个测点对应的子图中上图为视电阻率, 下图为阻抗相位. 图中红色和蓝色实线分别为三维反演模型中 $X Y$ 和 $Y X$ 分量的响应

$$
\Phi=\mathbf{X}^{-1} \mathbf{Y}
$$

式中, $\mathbf{X}$ 和 $\mathbf{Y}$ 分别代表阻抗张量的实部和虚部. 相位张 量椭圆可展示的信息包括最大相位 $\left(\boldsymbol{\Phi}_{\max }\right)$, 最小相位 $\left(\boldsymbol{\Phi}_{\min }\right)$, 参考轴方位 $(\alpha)$ 和二维偏离度 $(\beta)$. 当区域电性结 构为一维时, 相位张量椭圆的长、短半轴长度相同, 椭 圆退化为圆形; 当区域电性结构为二维时, $\beta$ 为 $0^{\circ}$, 相位 张量的长、短半轴分别对应两种极化模式的相位，椭 圆的长轴平行或垂直于构造走向, 当 $\beta$ 接近于 $0^{\circ}$, 比如 $|\beta|<3^{\circ}$ 时可近似为二维结构(Booker, 2014); 当区域电性 结构为三维时, 相位张量粗圆的长、短轴分别代表电 流最大和最小的两个方向, $\beta$ 不等于 0 , 其值随三维性 增强而增大(Caldwell等, 2004).
图3展示了三个周期下的相位张量椭圆平面分布. 在周期为 $0.12 \mathrm{~s}$ 时, 研究区西部的大部分测点二维偏离 度 $\beta<3^{\circ}$, 并且形状接近代表一维结构的圆形, 反映一维 特征; 而东部断裂密集部分的相位张量椭圆相反, 多数 测点二维偏离度 $\beta>3^{\circ}$, 说明断裂的存在使地下电性结 构更复杂. 在周期为 108 和 $1449 \mathrm{~s}$ 时, 大部分测点的二 维偏离度 $>3^{\circ}$, 相位张量椭圆的长短轴比值大, 且主轴 方向不统一, 表明地下深部复杂的电性结构. 因此, 需 要对观测数据采用三维反演方法以得到更可靠的电性 结构模型.

\section{3 反演计算}

三维反演采用ModEM开源程序包(Egbert和Kel- 


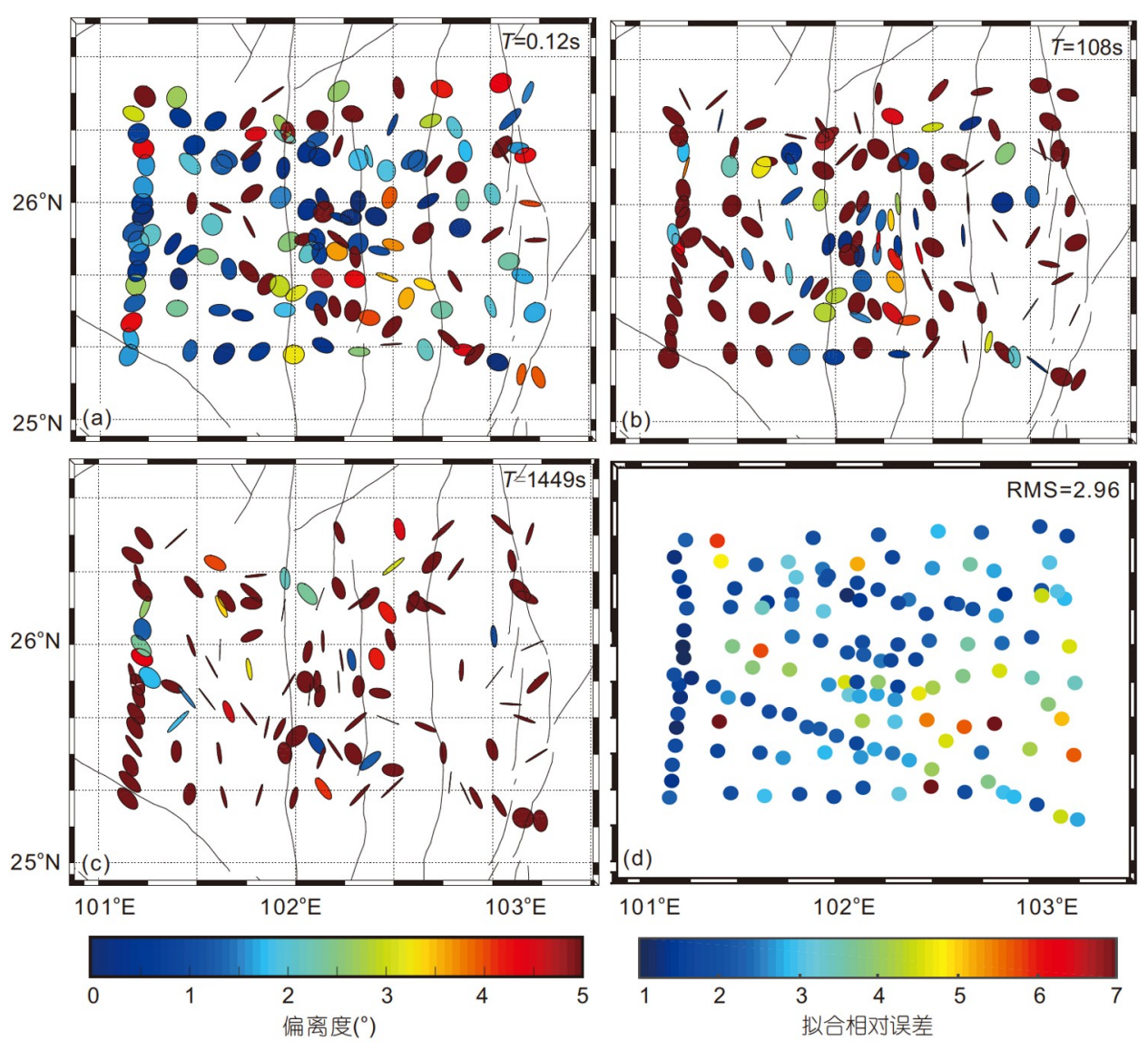

图 3 典型频率相位张量分析结果与测点平均拟合差平面分布

(a) (c)分别为周期 0.12、108和1449s的相位张量椭圆; (d)为各测点的拟合相对误差

bert, 2012; Kelbert等, 2014), 反演数据为全阻抗数据, 我们只选取了高质量的频段进行反演，其中宽频大地 电磁的频段为 $100 \mathrm{~Hz} 2000 \mathrm{~s}$ ，长周期大地电磁的频段 为 $10 \sim 10000 \mathrm{~s}$ ，最终在频段 $0.01 \sim 5000 \mathrm{~s}$ 范围内等对数间 隔选取 27 个频点. 四个阻抗分量门槛误差设置为 $5 \% \times$ $\left|Z_{x y} \cdot Z_{y x}\right|^{1 / 2}$ ，初始模型在水平方向核心区域以 $3 \mathrm{~km} \times 3 \mathrm{~km}$ 的规则网格剖分，以保证每个网格上最多有一个测点, 扩展区域以 1.3 的几何因子增长扩展 15 个网格. 垂直方 向首层厚度为 $50 \mathrm{~m}$, 以 1.1 的比例增加, 共设置 80 个网格 (不计空气层), 最终反演模型网格总数为 $86 \times 108 \times 80$.

针对反演多解性问题，分别采用50、100、 $500 \Omega \cdot \mathrm{m}$ 均匀半空间作为初始模型，并给定不同的模 型圆滑因子 $(0.2 、 0.3 、 0.4)$ ，进行多次试算，所有结 果模型都具有类似的深部电性结构特征. 最后选择 $100 \Omega \cdot \mathrm{m}$ 均匀半空间做初始模型，反演圆滑因子为 0.3 , 反演经 125 次迭代后停止的结果，最终RMS拟合差为 2.96(图3d).

\section{4 反演结果}

\section{1 三维电阻率结构模型}

图4和图5分别给出了三维电阻率模型的水平切面 和纵断面图, 共解释了 3 个高阻体(R1 R3) 和 8 个高导体 (C1 C8). 从整体上来看, 小江断裂带系统背景电阻率 中上地壳相对较高、中下地壳和上地幔较低.

(1) R1 高阻体广泛分布于研究区中上地壳, 其中在 绿汁江断裂、易门断裂、普渡河断裂和小江断裂之间 的上地壳形成三条较为明显的南北向高阻带分界线 (图4a), 并有部分穿过小江断裂带, 使得小江断裂带在 中上地壳表现为不连续的低阻反映 $(\mathrm{C} 7 、 \mathrm{C} 6$ 和 $\mathrm{C} 4)$ (图 $4 \mathrm{a}$ 和 $5 \mathrm{~d})$ ，与地震 $\mathrm{P}$ 波地壳速度结构体现的分区特性一 致(胥䝠等，2013)，Wei等(2013)结果也显示小江断裂 

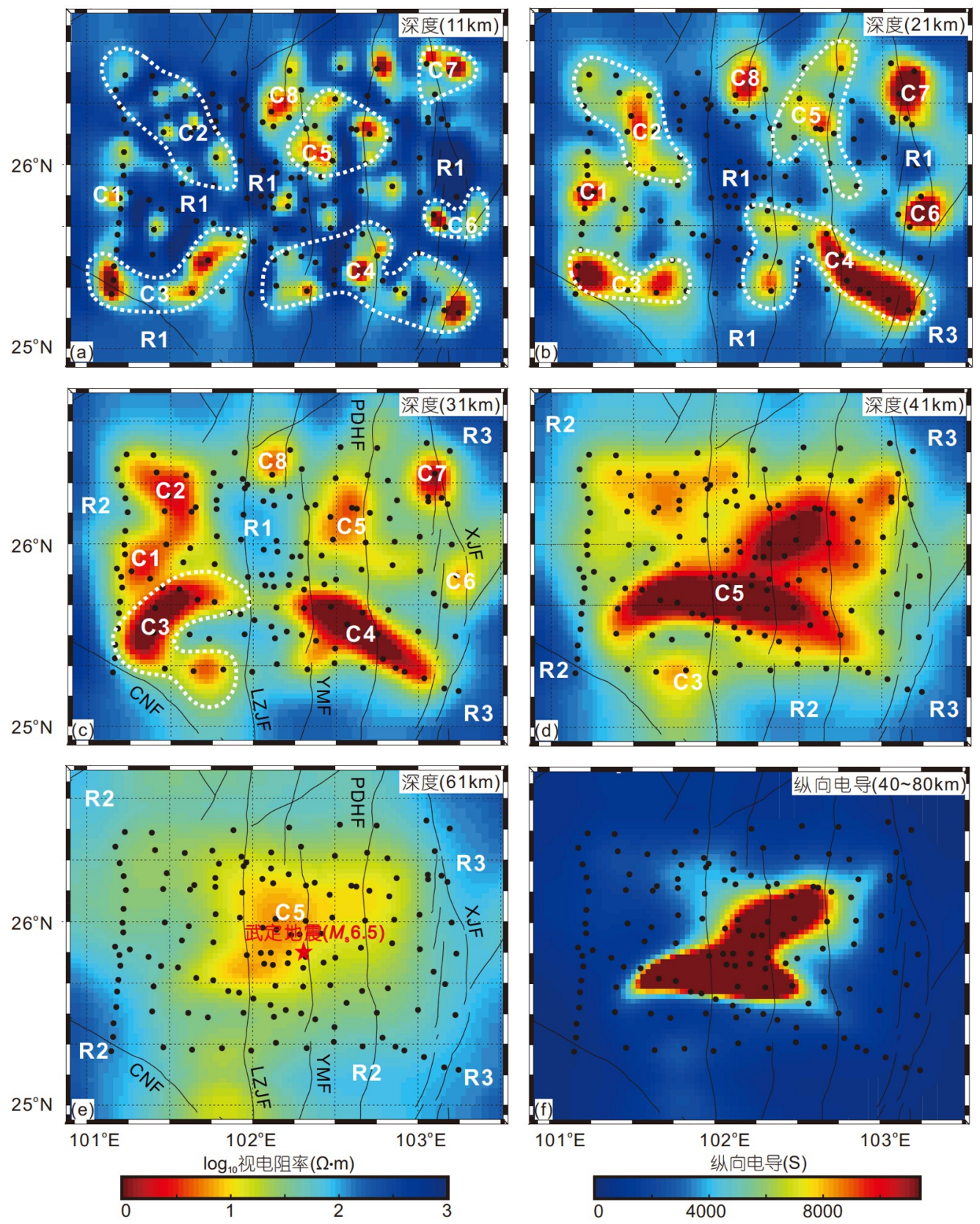

图 4 电阻率模型不同深度平面分布图

(a) (e) 分别为 $11 、 21 、 31 、 41$ 和 $61 \mathrm{~km}$ 深度水平切片, $\mathrm{C} 1 \sim \mathrm{C} 8$ 为高导异常体, R1 R3 为高阻异常体; (e)中红色五星为 1995 年 10 月 24 日武定地震 $\left(M_{\mathrm{S}} 6.5\right)$ 震中平面位置; (f)为纵向电导图 $(40 \sim 80 \mathrm{~km})$

带为高-低速相间的异常结构.

(2) R2 高阻体为川滇地块中下地壳和上地幔的高 阻反映，结果显示研究区西侧的电阻率更高 $(>1000 \Omega \cdot m)$, 而几条南北向断裂经过的区域较低，表 明小江断裂带系统受到地壳构造活动和青藏高原物质
流的破坏和改造作用.

（3） R3 高阻体为华南地块中下地壳和上地幔的高 阻反映, 可能是华南地块向西俯冲的电性结构证据, 与刘福田等(2000)地震层析成像结果揭示的滇西特提 斯造山带下高速异常类似. 

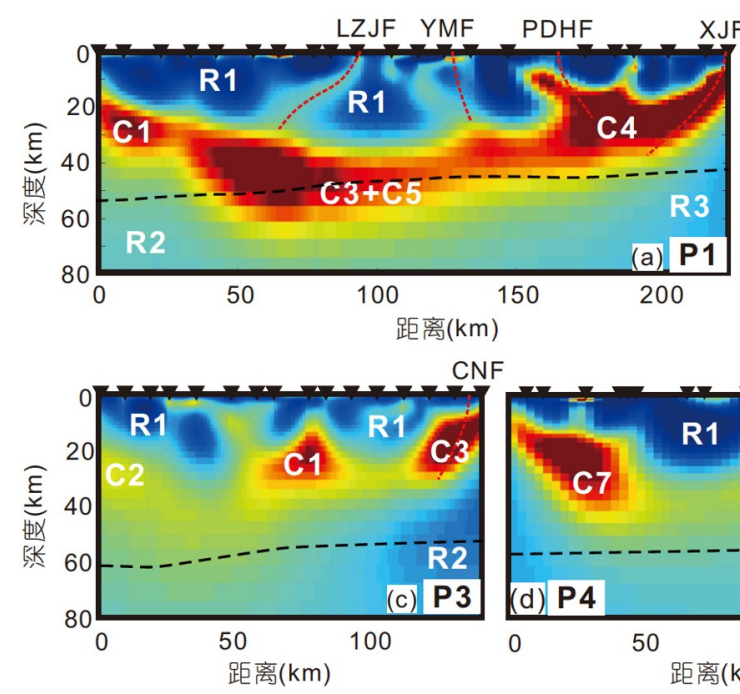

CNF

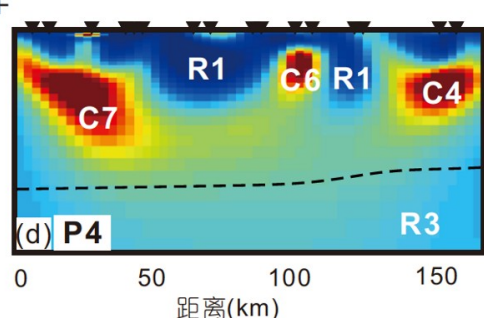

LZJF YMF

PDHF

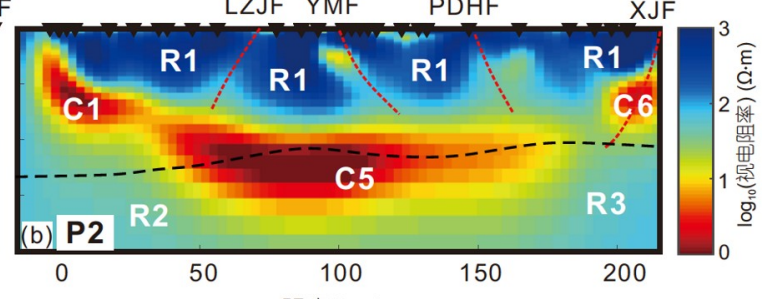

距离 $(\mathrm{km})$

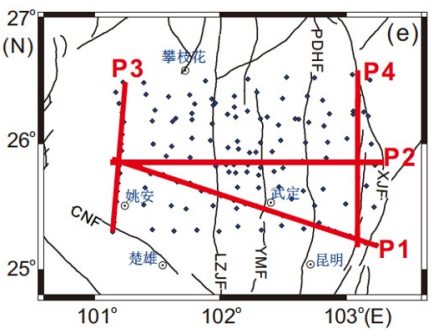

图 5 电阻率断面图

(a) (d)分别为P1 P4剖面电阻率断面图, 红色虚线为地表断裂深部推测延伸, 黑色虚线为Moho面(Xu等, 2020); (e)为剖面位置分布示意图

(4) $\mathrm{C} 1$ 和 $\mathrm{C} 2$ 高导体为绿汁江断裂西侧的中上地壳 低阻异常反映, 在中下地壳与研究区南侧的低阻异常 C3相连接(图4a 4c).

(5) C3 和C4高导体为两个地壳异常体, 其中C3位 于绿汁江断裂带西侧, C4低阻体沿易门断裂带向小江 断裂带发育(图4a 4c 和图 $5 a$ ), C3 和 C4 在中下地壳呈东 西向分布, 可能是受周边高阻块体阻挡发生变形的结 果, 该现象与三维P波结果(吴建平等, 2013)较为相似.

(6) C5 高导体为深度达上地幔的一个规模较大的 低阻异常, 其向上与地壳异常体 $\mathrm{C} 3$ 和 $\mathrm{C} 4$ 相连接 (图 $4 \mathrm{c} \sim 4 \mathrm{e}$ ). 结合 40 80km的纵向电导图(图4f)可以看出C5 在横向上总体呈现为北东-南西方向发育的趋势.

(7) $\mathrm{C} 6$ 和 C7高导体为小江断裂带中上地壳低阻异 常反映, 其与C4低阻体南北向形成高-低阻相间的结构 特征, 小江断裂带中下地壳表现为相对低阻特征, 说明 小江断裂带整体为岩石圈尺度的深大断裂(图 $4 \mathrm{~d}$ 和 图5).

(8) C8高导体为研究区易门断裂北段中上地壳低 阻异常反映(图4a 4c).

\section{2 模型灵敏度测试}

由于地球物理反演的非唯一性, 为检验电阻率模 型及异常体的可靠性, 需要对模型中主要异常体开展 灵敏度测试. 测试方法是修改异常体的电阻率值, 然 后通过三维正演得到修改后模型的响应数据, 并将其
与原始观测数据反演模型的拟合情况和响应数据对 比, 进而评价模型中异常体的可靠性.

本次研究对模型中主要低阻异常体 $(\mathrm{C} 1 、 \mathrm{C} 3 、 \mathrm{C} 5$ 和C6)进行了灵敏度测试, 结果均显示以上异常体是真 实可靠的. 以深部高导体 $\mathrm{C} 3$ 和 $\mathrm{C} 5$ 为例, 由于两个异常 体在Moho面附近连通成为一个整体异常, 因此作为一 个整体进行测试. 分别将异常体24 60、34 70、 $44 \sim 80 \mathrm{~km}$ 三个深度范围的电阻率修改为 $1000 \Omega \cdot \mathrm{m}$, 得到 的测试结果如图6所示. 对应于底面埋深为 60 和 $70 \mathrm{~km}$ 深度的可靠性测试结果(图6a、6b), 异常体上方大部分 测点拟合差增加 0.5 以上, 视电阻率曲线在 $100 \mathrm{~s}$ 附近开 始明显抬升, 阻抗相位曲线也相应的变化. 对于底面深 度为 $80 \mathrm{~km}$ 的可靠性测试结果, 异常体上方少数测点拟 合差依然明显增加, 大部分测点拟合差变化不明显. 这 表明被测试的异常体 $\mathrm{C} 3$ 和 $\mathrm{C} 5$ 是真实存在且可靠的，但 是其底界面可能高于 $80 \mathrm{~km}$, 这可能是由于长周期大地 电磁测点数量和低频频段的限制, 未能很好的刻画异 常体的底界面. 因此, 本次研究纵断面深度选择为 $80 \mathrm{~km}$, 并重点对 $80 \mathrm{~km}$ 以上的异常体特征进行解释.

\section{5 讨论}

\section{1 低阻异常成因分析}

岩石圈的低阻异常通常是流体(含盐水流体、部 分熔融)和高导矿物质(石墨、金属硫化物、铁的氧化 

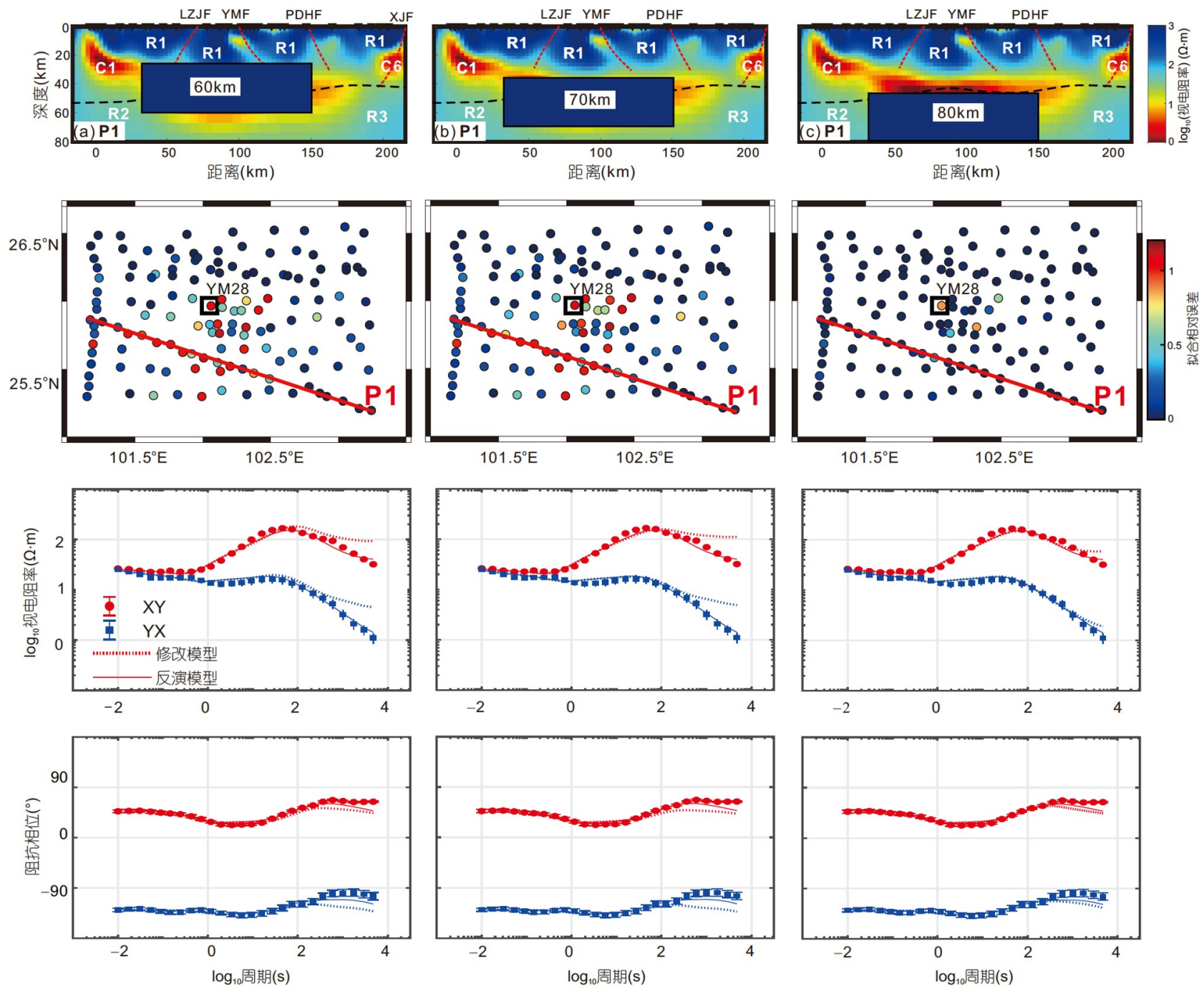

图 6 异常体灵敏度测试结果

物、含水矿物等)引起的(Chave和Jones, 2012; Selway, 2014). 根据电阻率模型主要低阻异常特征，我们分为 中上地壳、下地壳和上地幔两部分来具体讨论研究区 低阻异常的成因.

\subsection{1 中上地売低阻异常}

研究区上地壳观测到的条带状异常与地表断层有 较好的对应关系，其低阻异常很有可能是断裂带中含 盐水流体引起的(Unsworth和Bedrosian，2004b)．前人 研究表明，地表水下渗的最大深度是作用在流体上的 压力和流体静压力相等的位置, 对应深度约 $10 \mathrm{~km}$ (Foumier, 1991; Frost和Bucher, 1994). 对于深度 $<10 \mathrm{~km}$ 的低
阻异常，假设含盐水流体电阻率为 $0.03 \sim 0.3 \Omega \cdot \mathrm{m}$ ，根据 双相Archie公式(Archie, 1942; Glover等, 2000), 可用体 积占比为 $0.03 \sim 0.3 \%$ 的含盐水流体来解释(图7a).

中上地壳广泛分布的小型低阻体 $(\mathrm{C} 1 、 \mathrm{C} 2 、 \mathrm{C} 6$ 、 C7)低阻成因可能性较多. 上地壳的温度比较低, 部分 熔融不可能存在。若这些低阻体是含盐水流体 $(0.03 \sim 0.3 \Omega \cdot \mathrm{m})$ 引起的, 则需要体积百分比 $3 \sim 30 \%$ 的含 盐水流体才可以解释其对应的 $1.0 \Omega \cdot \mathrm{m}$ 的电阻率(图7a), 但在地壳深度超过 $10 \mathrm{~km}$ 的这么高的岩石孔隙体积比 是不可能的, 含盐水流体无法作为解释低阻异常成因 的唯一因素.

排除以上可能，高导矿物质可能作为低阻成因的 

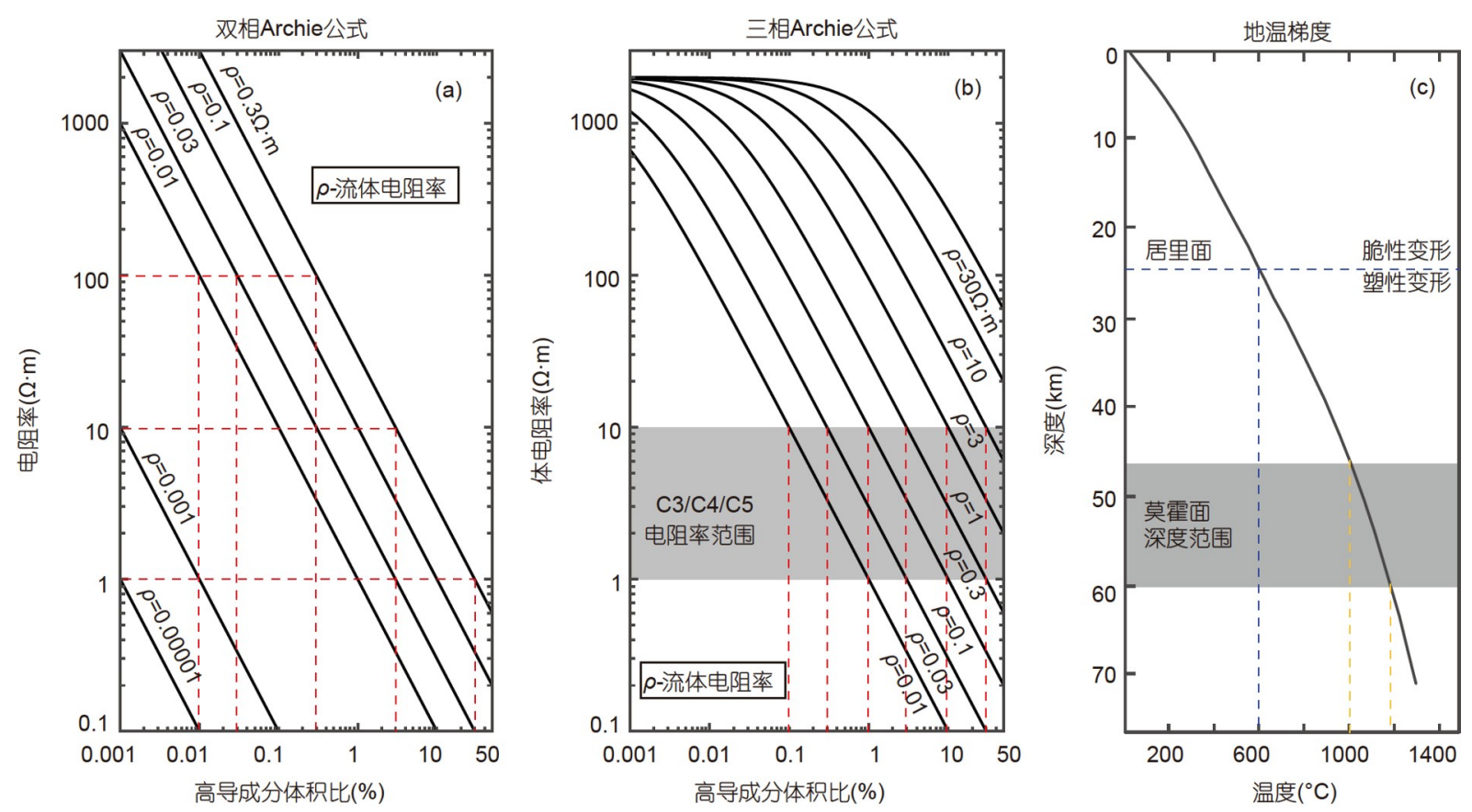

图 7 研究区岩石圈低阻异常成因分析

根据双相Archie公式a和三相Archie公式b计算的对应不同高导体的体积百分比的岩石电阻率的值(Archie, 1942; Glover等, 2000). 其中胶结指 数 $m=1$, 三相Archie公式中的导电岩石的电阻率设置为 $2000 \Omega \cdot \mathrm{m}(\mathrm{Li}$ 等, 2003). (c) 研究区地温梯度曲线(周真恒和向英才, 1997)和对应的居里面 温度为 $600^{\circ} \mathrm{C}$ 的深度, 以及莫霍面的温度范围

解释之一. 而事实上小江断裂带也是青藏高原东南缘 重要的斑岩铜钼金成矿区之一(侯增谦等, 2004). 纯石 墨的电阻率为 $0.00001 \Omega \cdot \mathrm{m}$, 纯金属硫化物的电阻率为 $0.01 \Omega \cdot \mathrm{m}$, 纯磁铁矿的电阻率 $0.0001 \Omega \cdot \mathrm{m}$ (Yoshino和 Noritake, 2011; Jones等, 1997; Myer等, 2013), 要解释 观测到的低阻体 $1.0 \Omega \cdot \mathrm{m}$ 的电阻率, 所需要的体积百分 比分别为 $0.001 \% 、 1 \% 、 0.01 \%$ (图7a). 含水矿物的电 阻率比普通壳内岩石低一个数量级(Lee等, 1983; Bell 和Rossman, 1992), 但是这不足以解释观测到的低阻.

因此, 对于中上地壳低阻, 深度 $<10 \mathrm{~km}$ 的部分可以 用含盐水流体解释, 深度 $>10 \mathrm{~km}$ 的部分需要用含盐水 流体和高导矿物质共同来解释.

\subsection{2 下地売和上地幔低阻异常}

关于下地壳和上地幔低阻异常体的解释, 前人围 绕是水(包括含盐水流体和视无水矿物质中的结构水), 是石墨，还是熔融，有过深入的讨论(Yang等，2012; Wannamaker, 2000; Yardley和Valley, 1997; Hyndman等, 1993). 中下地壳低阻体的电阻率 $1.0 \Omega \cdot \mathrm{m}$, 需要 $>3 \%$ 体积 比的含盐水流体 $(0.03 \sim 0.3 \Omega \cdot \mathrm{m})$ 来解释(图7a), 这个岩石
孔隙比值对于下地壳岩石明显过高, 所以排除含盐水 流体作为低阻成因解释. Yoshino和Noritake(2011)实验 表明石墨在温度 $>700^{\circ} \mathrm{C}$ 时不能形成岩石缝隙的导电 层, 而研究区下地壳的温度为 $600 \sim 1200^{\circ} \mathrm{C}$ (周真恒和向 英才, 1997; 图7c), 所以石墨引起低阻的可能性也排除.

部分熔融以及视无水矿物质中的结构水都可以引 起地震低速和电性低阻异常(Özaydın和Selway, 2020; Unsworth和Rondenay, 2013), 可以作为小江断裂带系 统可能的导电机制重点讨论. Yang等(2012)实验证明 视无水矿物中的结构水引起的下地壳最低电阻率是 $10.0 \Omega \cdot \mathrm{m}$, Özaydın和Selway(2020)的分析结果认为深 度 $<125 \mathrm{~km}$ 的上地幔低阻体无法仅靠视无水矿物质中 的结构水来解释. 因此视无水矿物质中的结构水可能 是引起低阻的部分原因, 但还需其他的降低电阻率原 因来解释观测到的低阻.

干燥的下地壳岩石在温度 $>1000^{\circ} \mathrm{C}$ 才可能熔融 (Hashim等, 2013), 因此只有在含水的情况下下地壳和 上地幔才会发生部分熔融, 这也间接证明视无水矿物 质中结构水的存在. 前人研究证明地壳内熔融体的电 阻率为 $<3.0 \Omega \cdot \mathrm{m}$ (Comeau等, 2015), 如果只考虑熔融降 
低电阻率, 那需要体积比 $>30 \%$ 的部分熔融才能解释下 地壳和上地幔的异常(图7b)，考虑到视无水矿物质中 的结构水存在，这个体积比可 $<30 \%$. 因此，视无水矿 物质中的结构水和部分熔融是下地壳和上地幔低阻异 常的可能成因.

\section{2 小江地区地震孕震环境分析}

研究区位于中国大陆内部南北地震带中段, 地震 灾害频发, 自1970年有历史记录以来, 共发生 $M_{\mathrm{S}}>6.0$ 地 震 6 次. 根据地震活动和电性结构的空间分布特征, 大 致可以把研究区地震划分为三大类，第一类是主要发 生在活动断裂附近的构造地震 (图8a橙色圈内), 该类 型地震与大型走滑断裂与不同块体之间的相对运动有 关, 包括武定 $M_{\mathrm{S}} 6.5$ 地震在内, 在电性结构特征上主要 发生在中上地壳与易门断裂带等活动断裂对应的中低 阻条带内部及周缘(图8b). 第二类是集中发生在地表没 有明显活动断裂的地震，如大姚和姚安等区域的地震 (图8a白色圈内), 主要发生在下伏低阻体边缘及周围 的中高阻区域内(图8c). 第三类是较为分散的地震, 分 布无明显规律, 但是总体主要分布在中上地壳内, 剖面 下方的高阻块体与低阻体之间靠近高阻体的一侧, 与 青藏高原东缘主要地震规律一致(王绪本等, 2017).

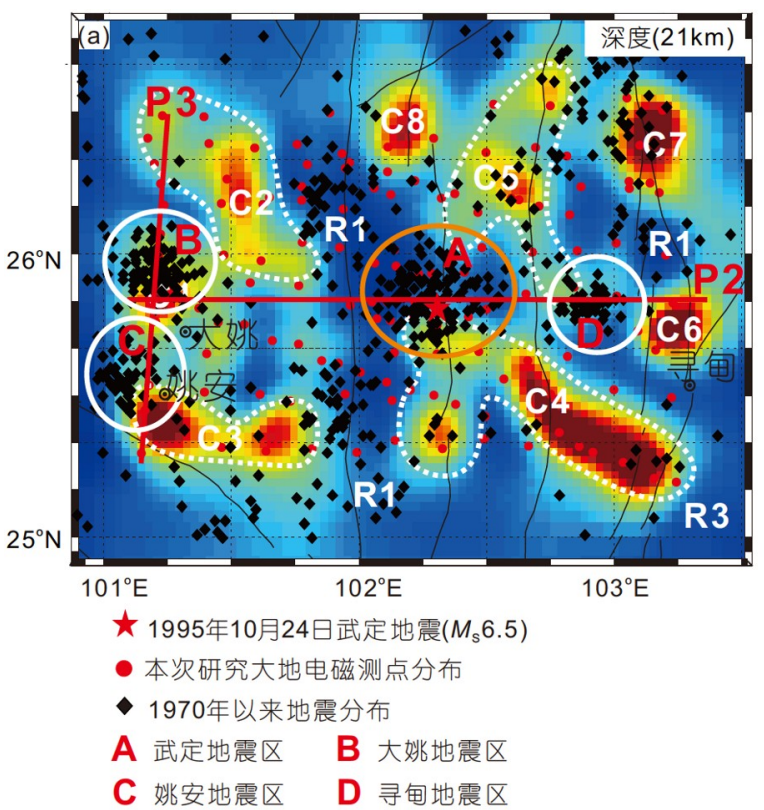

\subsection{1 第一类地震}

青藏高原的侧向挤压驱动川滇地块的东南运动 (邓启东等, 2002), 致使小江断裂带系统的走滑断裂呈 现左旋剪切走滑为主的特征，区域压应力仍沿断层走 向在断层面形成剪切力，较强的走滑断裂活动将造成 块体不稳定从而造成地震的发生. 深部流体运移与地 震活动密切相关(Thompson和Connolly, 1995; Cai等, 2017), 来自青藏高原的弱物质流沿断裂带和软弱区域 上涌, 可显著降低断裂带内的摩擦力, 促进断裂运动, 导致断层失稳并发生移动和地震成核作用(惠钢等, 2021; 唐裕等，2021); 而地震的发生和断裂长期的走 滑/剪切活动反过来产生热量会降低中下地壳的电阻 率和黏度(Leloup等, 1999), 促进流体的运移. 另一方 面, 地表水沿断层向下渗透也可能激活断层从而诱发 浅层地震(Pandey和Chadha, 2003).

\subsection{2 第二类地震}

第二类地震主要发生在高导体(如C1)两侧的中高 阻区域. 高导体可以解释为阻止应力积累的一个韧性 带, 其上覆的中高阻区是一个脆性区, 将积累应变并 最终发生脆性变形(图8b 8c). C1向下延伸与来自青藏 高原的物质流相连, 构成了深部流体向上运移的通道,
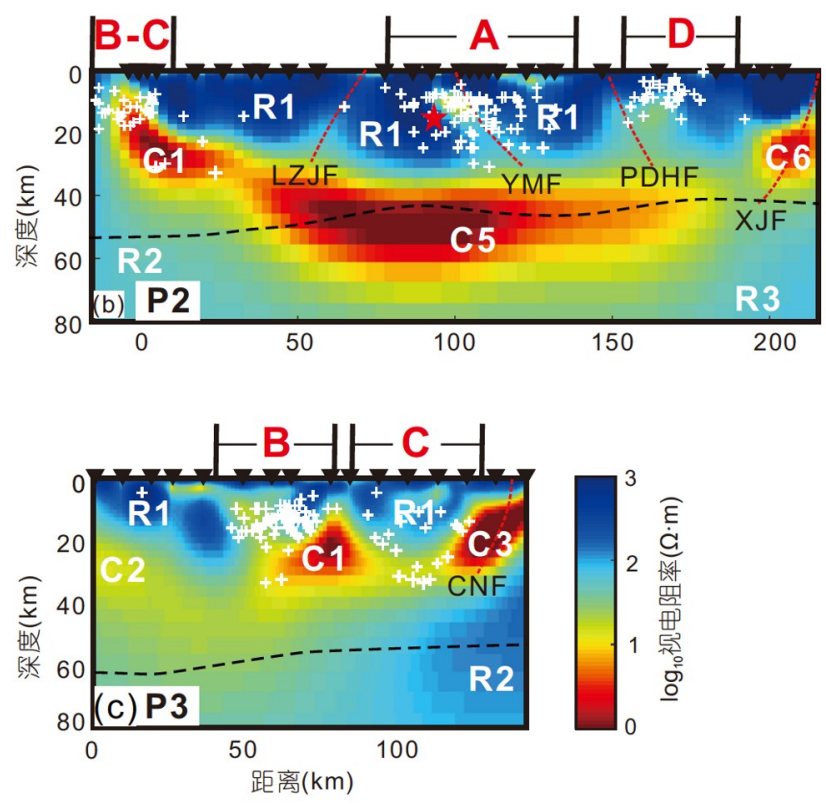

图 8 地震分布与电性结构的关系

(a) 震级 $M_{\mathrm{S}}>3.0$ 地震平面分布, 底图为 $21 \mathrm{~km}$ 深度电阻率切面; (b) P2剖面电阻率模型及剖面两侧 $10 \mathrm{~km}$ 范围内地震投影; (c) P3剖面电阻率模型 及剖面两侧 $10 \mathrm{~km}$ 范围内地震投影 
这意味着这个区域中上地壳的地震活动可能是中下地 壳深部流体迁移向上迁移触发的. 地壳的强度随流体 含量变化而改变(Kohlstedt等, 1995), 流体的存在将降 低地壳的强度, 减少脆性区在深度上的扩展, 并将应力 积累集中到中上地壳的中高电阻刚性区域(Gürer和 Bayrak, 2007; Li D W等, 2021), 最终导致地壳的破裂 和地震的成核.

\subsection{3 第三类地震}

第三类地震可能是由于区域性强地震改变地震区 周围的应力场, 进而通过应力传递的形式触发产生的 (Parsons等, 2008; Han等, 2017; Zhang等, 2021). 川滇 地区地震活动强烈, 除小江断裂带附近的地震, 包含印 支地块、华南地块及龙门山构造带等相邻地块和构造 区域发生的强地震, 也会通过地块和构造传递并扰乱 小江地区的应力场, 进而诱发后续地震, 这符合地震的 应力触发理论(Stein, 2003). 因此, 该类型地震可能是川 滇地区多次强震导致局部应力调整引起的地震事件.

综上所述, 第一类地震是由于构造活动和流体运 移等因素协同作用引发的, 第二类地震是由于深部流 体向上运移触发的, 第三类则是由区域性强地震使应 力场改变而诱发的.

\section{3 峨眉山古地幔柱与小江断裂带的关系}

峨眉山大火成岩省是中国境内最早获得国际学术 界广泛认可的大火成岩省, 大致形成于 $250 \mathrm{Ma}$ 左右. 二叠纪峨眉山玄武岩分布广泛, 面积达到 $2.5 \times 10^{5} \mathrm{~km}^{2}$, 厚度可达 $700 \mathrm{~m}$ (图1a; 徐义刚和钟孙霖, 2001 ; 徐义刚 等, 2013). 峨眉山大火成岩省的形成普遍认为与古地 幔柱的活动有关, 古地幔柱的火山作用会改变壳幔物 质成分, 作为古地貌的活动遗迹记录在岩石圈结构中 并被各种地球物理方法观测到(Chen等, 2015; 徐涛等, 2015). 本研究区位于其内带和中带交界的区域(图1b), 前人研究表明地幔柱头在内带下方与上覆岩石圈接触 (Xu等, 2004), 因此小江岩石圈受到地幔柱活动的强烈 改造作用. 前人研究表明小江断裂带深部结构的形成 与峨眉山古地幔柱密切相关(徐涛等, 2015; 黄周传等, 2021), 对小江地区进行电性结构研究, 对于提高对古 地幔柱深部结构的认识及其对区域构造演化的理解具 有重要作用.

地质地球物理研究结果显示峨眉山大火成岩省以
攀枝花为中心, 地壳呈现为明显的高速、高阻、高密 度特征, 重力异常最大值达到 $150 \mathrm{mGal}$, 可能是古地幔 柱活动导致大量基性和超基性幔源物质上涌侵入地壳 的结果(Peate和Bryan, 2008; 徐义刚等, 2013; 吴建平 等, 2013; Deng等, 2014; Chen等, 2015; 徐涛等, 2015; 程远志等, 2017; Li等, 2020; 张智奇等, 2020; Li W等, 2021). 本次研究区位于核心区域的东南部, 中上地壳 (图4a、4b和图5)呈现为相对高阻特征, 与该区域的中 上地壳高速异常有较好的对应关系(张智奇等, 2020), 为冷却玄武岩的特征反映; 上地壳同时也分布着多个 低阻异常, 为走滑断裂活动对大火成岩省强烈破坏改 造的结果. 前人研究揭示了小江断裂带中下地壳显著 低速、低电阻、强衰减的特点(Yao等, 2008; Zhao等, 2013; Bao等, 2015; Huang等, 2018; Li等, 2019; 张智奇 等, 2020; 黄周传等, 2021), 与本次模型呈现的低电阻 特征一致. 该低阻可能为来自青藏高原的弱物质流受 以攀枝花地区为核心的峨眉山大火成岩省表现为壳内 高速高阻的坚硬块体所阻挡( $\mathrm{He}$ 等, 2003; 吴建平等, 2013; 徐涛等, 2015; Chen等, 2015; Qiao等, 2018; 张 智奇等, 2020; 图9), 分为沿大型走滑断裂带的两个分 支中东侧分支的反映( $\mathrm{Li}$ 等, 2020), 详细过程将在下一 节中介绍.

结合地球化学、地震等资料(Farnetani等, 1996; Xu等, 2004; 徐涛等, 2015; 滕吉文等, 2019), 推测小 江断裂带系统地壳结构经历了如下演化过程: 研究区 地幔在二叠纪峨眉山大火成岩省形成时期火山作用下 产生大量的基性超基性岩浆, 以侵入和底侵的方式侵 入地壳; 经过长时间的平静, 热的岩浆岩固结形成以 攀枝花为中心的高速高阻物质; 新生代以来受印度板 块与欧亚大陆的碰撞挤压、来自青藏高原中部深部物 质东南向流动等综合影响, 壳幔形成的部分熔融流体 沿小江断裂、绿汁江断裂等断裂上涌及大型断裂本身 走滑作用对峨眉山大火成岩省内带高阻高速块体进行 强烈破坏改造; 最终形成现今小江断裂带系统南北向 断裂之间中上地壳高低阻条带相间、中下地壳呈现低 阻低速的特征.

因此, 本次结果同样支持小江断裂带系统中上地 壳的运动变形机制符合刚性块体挤出模型, 并沿大规 模走滑断裂挤压滑动的观点(Tapponnier等, 1982, 2001; Yao, 2012; Fu等, 2017; Qiao等, 2018; 张智奇等, 2020; 高天扬等, 2021). 


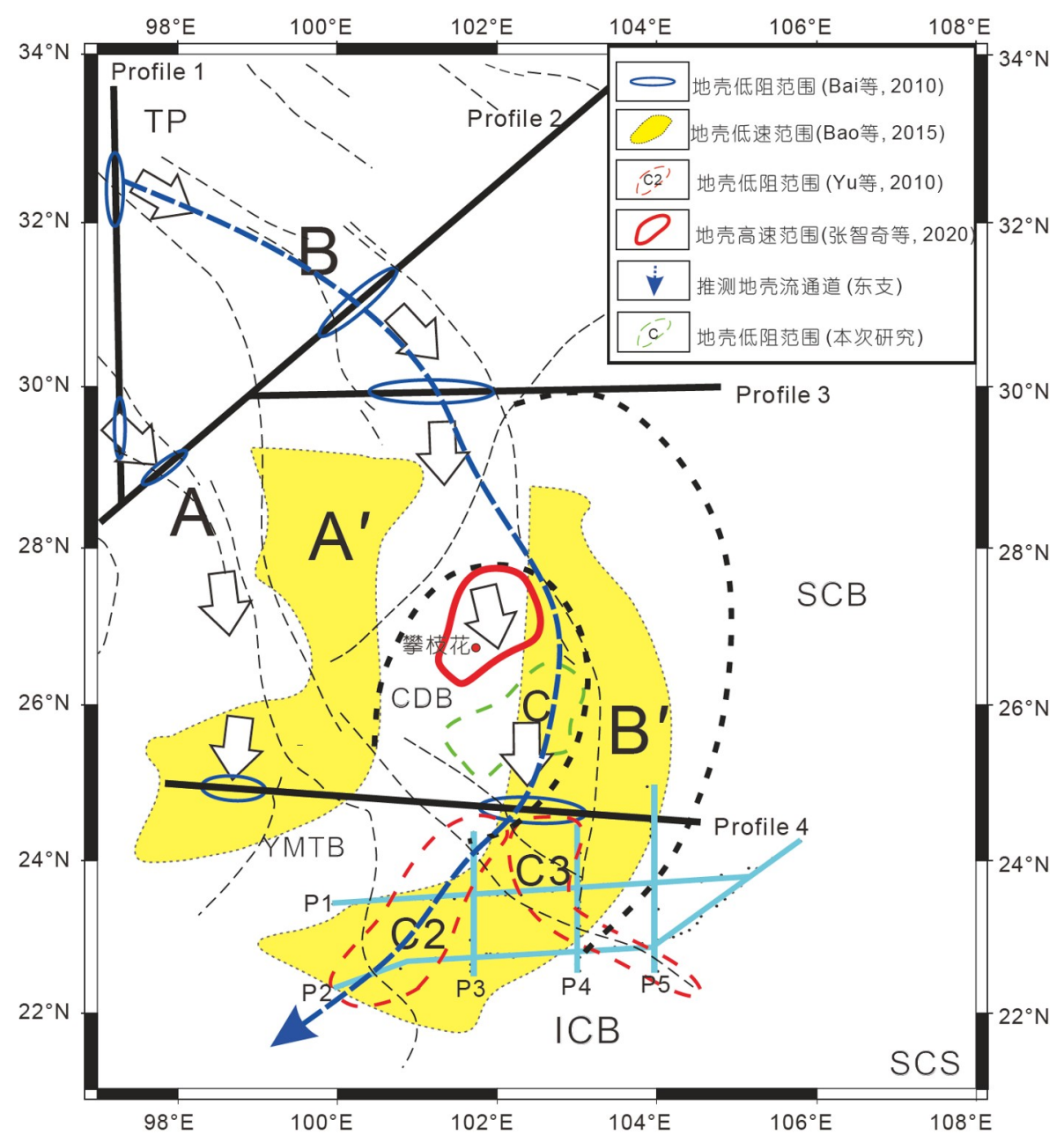

图 9 青藏高原东南缘地壳异常分布图

Profile 1 4为Bai等(2010)在青藏高原东南缘实施的4条剖面, 白色箭头为推测地壳流通道(A和B); 黄色区域为Bao等(2015)得到低速区域及推 测的地壳流通道 $\left(\mathrm{A}^{\prime}\right.$ 和 $\left.\mathrm{B}^{\prime}\right)$; 红色范围为根据张智奇等(2020)研究给出的峨眉山大火成岩省核心的范围; 蓝色虚线为结合前人研究和本次模型推 测地壳流通道(东支). 修改自Hu等(2018)

\section{4 深部物质运移机制}

青藏高原东南缘中下地壳的强度比上地壳的强度 小几个数量级, 因此“地壳流模型”很好地解释了地形 变化与上地壳缩短明显不一致的问题(Shen等，2005; Royden等，2008)，已逐渐成为解释青藏高原东南缘动 力学机制的主要模型.

在青藏高原东南缘开展的深部地球物理研究提供 了低速、低电阻异常存在的证据，且多数研究支持存 在东西两个中下地壳软弱物质流动通道(Bai等，2010; Zhao等, 2013; Bao等, 2015; Li等, 2016; 郑晨等, 2016; 张智奇等，2020), 但不同的数据和不同反演方法得到 的地壳流通道的位置和形态不完全相同. Bao等(2015)
通过接收函数和瑞利波联合反演，揭示在青藏高原东 南缘存在两个低速体, 并推断为地壳流通道, 其中东 侧的低速体经小江断裂带系统向西南穿过红河断裂带 进入印支地块(图9). Zhao等(2013)通过Lg波衰减成像 在青藏高原东南缘发现了两个复杂的高衰减异常，推 断为物质流动通道. 电性结构研究也给出了类似的结 果, Bai等(2010)利用大地电磁研究表明低电阻率异常 仅位于地形变化剧烈的两个边缘区域, 认为虽然这些 特征可能表征流动通道，同时也可能是活跃走滑剪切 带的反映(图9). Yu等(2020)也有类似的结论, 认为可 能同时是岩石圈尺度的红河断裂带和上地幔物质上涌 通道的反映(图9). 
本次研究区域位于Yu等(2020)研究区区域的北部, 包含 $\mathrm{Li}$ 等(2020)部分数据，与Bao等(2015)研究区域南 部重合. 因此，我们可以通过新的小江断裂系统三维 电性结构模型与前人研究成果相结合来推测区域结构 特征. 三维电阻率模型显示Bai等(2010)提出的低阻通 道经过本次研究范围, 可以看出低阻异常向南与Bai等 (2010)剖面4的异常和 Yu等(2020)的C2和C3 异常相连 接(图9); 同时在绿汁江断裂西侧与Li等(2020)低阻异 常有较好的对应关系(图4c)，间接证明了Li等(2020)关 于峨眉山大火成岩省对青藏高原下地壳流阻挡观点的 正确性.

结合前人在研究区地壳流通道的研究成果, 推测 从青藏高原中部流出的弱物质流在青藏高原东南缘分 为两支，其中东支流经川滇地块被峨眉山古地幔柱活 动改造的岩石圈和华南地块阻挡，沿小江断裂带系统 转向西南方向，穿过红河断裂带进入印支地块. 该推 断与Qiao等(2018)给出的通道较为相似.

上地幔高导体异常(C5)是本次电阻率模型的另一 个重要特征, 该异常得到了很多深部地球物理成像研 究成果的证实, 认为青藏高原东部上地幔物质上涌对 中下地壳物质流有一定的补充作用(Lei等，2019). 大 地电磁成像结果(Li等，2019)同样显示地壳低电阻率
异常可以延伸至上地幔，推测是流体或熔融体沿断裂 上涌的反映. 三维P波速度结构(Huang等，2002; 吴建 平等, 2013)显示小江断裂带中部存在从地壳延伸至上 地幔的低速异常，推测与深部热作用有关. P波各向异 性层析成像(Wei等, 2013)显示, 小江断裂带 $102^{\circ} \sim 104^{\circ} \mathrm{E}$ 范围下地壳和上地幔呈现低速特征, 认为上地壳的地 震受到下地壳和上地幔的动力过程影响. 瑞利波层析 成像结果(Fu等，2017)显示小江断裂带系统从Moho至 $90 \mathrm{~km}$ 深度同样为相对低速, 认为可能是扬子克拉通西 缘受青藏高原挤压造成的热侵蚀.

前期研究对青藏高原东南缘深部热物质来源进行 了梳理(Yu等, 2020), 认为存在青藏高原中部(Huang等, 2015)、缅甸弧俯冲引起的地幔物质上涌( $\mathrm{Li}$ 等， 2008; Yang等，2015)和海南地幔柱(Yu等，2020)等多种来源 的可能. C5 异常位于川滇地块, 而前人研究结果显示 缅甸弧俯冲造成上涌通道的主要在红河断裂以西的区 域(Lei等, 2009; Wei等, 2013), 且C5异常产状较陡(图 $6 \mathrm{~d}$ 和6e), 未体现与红河断裂带北东侧上地幔电阻率异 常连通的特征. 综合以上地球物理证据并结合本次三 维电阻率模型, C5 可能是来自青藏高原地幔物质流沿 走滑剪切断裂系统上涌的体现.

因此，我们建立如图10所示的岩石圈结构示意图,

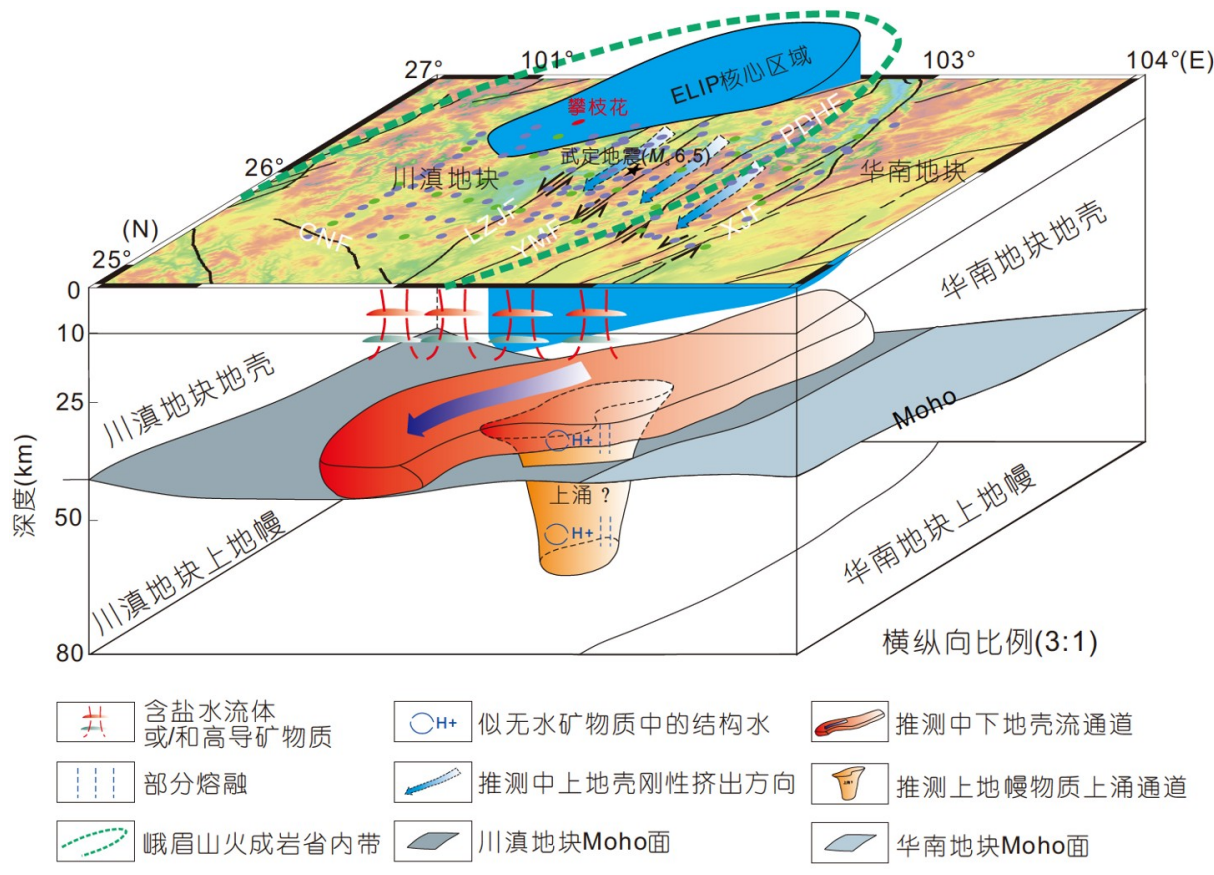

图 10 青藏高原东南缘小江断裂带系统岩石圈结构模型 
小江断裂带系统现今深部构造活动呈现为中上地壳沿 走滑断裂刚性挤出、中下地壳以地壳通道流方式塑性 蠕动、上地幔存在上涌的复杂模式，其对理解小江断 裂带及青藏高原东南缘的地壳形变和动力学演化起着 非常重要的作用.

\section{6 结论}

本文通过三维反演宽频带及长周期大地电磁密集 阵列观测数据获得了小江断裂带系统的岩石圈电性结 构，为小江断裂带及青藏高原东南缘深部物质运移及 孕震环境研究提供了新的观测约束.

(1) 详细分析和讨论主要低阻异常的成因, 推测中 上地壳低阻异常是含盐水流体和高导矿物质共同造成 的，而视无水矿物质中的结构水和部分熔融是下地壳 和上地幔低阻异常的可能成因.

（2）研究区内地震可以分为三类，主要由构造活 动、流体运移和应力场调整等因素协同作用影响; 地 震和深部流体活动之间互相影响，低阻流体的存在有 助于断裂发生剪切运动而诱发地震，反过来断裂活动 产生热量/增强流体连通性将降低地壳的强度，促进流 体的运移.

（3）小江断裂带系统在不同深度呈现出不同的变 形机制和物质运移模式: 刚性的中上地壳沿走滑断裂 带挤出、中下地壳以地壳通道流方式发生塑性蠕动、 上地幔存在上涌.

（4）来自青藏高原的壳内弱物质流经川滇地块时 受到峨眉山古地幔柱活动改造的岩石圈和华南地块阻 挡, 沿小江断裂带系统转向西南方向, 穿过红河断裂带 后进入印支地块.

\section{参考文献}

陈立春, 再勇康, 王虎, 李彦宝, 马兴全. 2013. 地表弱活动断裂6 7级 地震中长期预测技术要点与案例解析. 地震地质, 35: 480-489

程远志, 汤吉, 蔡军涛, 陈小斌, 董泽义, 汪利波. 2017. 青藏高原东缘 川滇构造区深部电性结构特征. 地球物理学报, 60: 2425-2441

邓启东, 张培震, 苒勇康, 杨晓平, 闵伟, 楚全芝. 2002. 中国活动构造 基本特征. 中国科学 $\mathrm{D}$ 辑: 地球科学, 32: 1020-1031

高天扬, 丁志峰, 王兴臣, 姜否. 2021. 利用接收函数、面波频散和ZH 振幅比联合反演青藏高原东南缘地壳结构及其动力学意义. 地 球物理学报, 64: 1885-1906
高原, 石玉涛, 王琼. 2020. 青藏高原东南缘地震各向异性及其深部 构造意义. 地球物理学报, 63: 802-816

侯增谦，钟大责，邓万明. 2004. 青藏高原东缘斑岩铜钿金成矿带的 构造模式. 中国地质, 31: 1-14

黄周传, 吉聪, 吴寒婷, 石宇通, 耿嘉琪, 徐弥坚, 韩存瑞, 徐鸣洁, 王 良书. 2021. 青藏高原东南缘地壳结构与变形机制研究进展. 地 球与行星物理论评, 52: 291-307

惠钢, 陈胜男, 顾斐. 2021. 流体-地质力学耦合建模表征水力压裂诱 发地震: 以加拿大Fox Creek地区为例. 地球物理学报, 64: 864875

李手, 汤吉, 董泽义, 肖骑涁, 詹绝. 2014. 云南南部地区深部电性结 构特征研究. 地球物理学报, 57: 1111-1122

刘福田, 刘建华, 何建坤, 游庆瑜. 2000. 滇西特提斯造山带下扬子地 块的俯冲板片. 科学通报, 45: 79-85

卢海峰, 何仲太, 赵俊香, 马保起, 王瑞. 2008. 元谋断裂晚第四纪活 动性定量分析. 地球科学一一中国地质大学学报, 33: 852-860

石否, 楼海, 王谦身, 卢红艳, 徐伟民. 2015. 攀西地区重力场特征及 地壳密度结构. 地球物理学报, 58: 2402-2412

唐裕, 翁爱华, 杨悦, 李世文, 牛建军, 张艳辉, 李亚森, 李建平. 2021. 松原地震与流体作用联系的大地电磁证据. 中国科学: 地球科学, 51: 134-149

滕吉文, 宋鹏汉, 董兴朋, 刘有山, 马学英, 间雅芬. 2019. 攀枝花古地 幔柱壳、幔结构与地球物理边界场特征. 地球物理学报，62: 3296-3320

王绪本, 余年, 高嵩, 罗威, 蔡学林. 2017. 青藏高原东缘地壳上地幔 电性结构研究进展. 地球物理学报, 60: 2350-2370

闻学泽, 杜方, 龙锋, 范军, 朱航. 2011. 小江和曲江-石屏两断裂系统 的构造动力学与强震序列的关联性. 中国科学: 地球科学, 41 : 713-724

吴建平, 杨婷, 王未来, 明跃红, 张天中. 2013. 小江断裂带周边地区 三维P波速度结构及其构造意义. 地球物理学报, 56: 2257-2267

吴熙彦, 徐锡伟, 于贵华, 程佳, 陈桂华, 安艳芬, 王启欣. 2018. 国家 川滇实验场地震地表破裂带分布图编制. 地震地质, 40: 27-41

胥颐, 杨晓涛, 刘建华. 2013. 云南地壳速度结构的层析成像研究. 地 球物理学报, 56: 1904-1914

徐涛, 张忠杰, 刘宝峰, 陈兓, 张明辉, 田小波, 徐义刚, 滕吉文. 2015. 峨眉山大火成岩省地壳速度结构与古地幔柱活动遗迹: 来自丽 江-清镇宽角地震资料的约束. 中国科学: 地球科学, 45: 561-576 徐锡伟, 闻学泽, 郑荣章, 马文涛, 宋方敏, 于贵华. 2003. 川滇地区活 动块体最新构造变动样式及其动力来源. 中国科学 $\mathrm{D}$ 辑: 地球科 学, 33(增刊): 151-162

徐义刚, 何斌, 罗震宇, 刘海泉. 2013. 我国大火成岩省和地幔柱研究 进展与展望. 矿物岩石地球化学通报, 32: 25-39

徐义刚, 钟孙霖. 2001. 峨眉山大火成岩省: 地幔柱活动的证据及其 熔融条件. 地球化学, 30: 1-9

俞维贤, 谢英情, 张建国, 杨继武. 2004. 昆明盆地周边地区主要断裂 
活动时代研究. 地震研究, 27: 357-362

张智奇, 姚华建, 杨妍. 2020. 青藏高原东南缘地壳上地幔三维S波速 度结构及动力学意义. 中国科学: 地球科学, 50:1242-1258

郑晨, 丁志峰, 宋晓东. 2016. 利用面波频散与接收函数联合反演青 藏高原东南缘地壳上地幔速度结构. 地球物理学报，59：32233236

周真恒, 向英才. 1997. 云南岩石圈地温分布. 地震地质, 19: 227-234

Archie G E. 1942. The electrical resistivity log as an aid in determining some reservoir characteristics. Trans AIME Soc Petrol Eng, 146: $54-62$

Bai D, Unsworth M J, Meju M A, Ma X, Teng J, Kong X, Sun Y, Sun J, Wang L, Jiang C, Zhao C, Xiao P, Liu M. 2010. Crustal deformation of the eastern Tibetan Plateau revealed by magnetotelluric imaging. Nat Geosci, 3: 358-362

Bao X, Sun X, Xu M, Eaton D W, Song X, Wang L, Ding Z, Mi N, Li H, Yu D, Huang Z, Wang P. 2015. Two crustal low-velocity channels beneath SE Tibet revealed by joint inversion of Rayleigh wave dispersion and receiver functions. Earth Planet Sci Lett, 415: $16-24$

Beaumont C, Jamieson R A, Nguyen M H, Lee B. 2001. Himalayan tectonics explained by extrusion of a low-viscosity crustal channel coupled to focused surface denudation. Nature, 414: 738-742

Becken M, Ritter O, Bedrosian P A, Weckmann U. 2011. Correlation between deep fluids, tremor and creep along the central San Andreas fault. Nature, 480: 87-90

Bell D R, Rossman G R. 1992. Water in Earth's mantle: The role of nominally anhydrous minerals. Science, 255: 1391-1397

Booker J R. 2014. The magnetotelluric phase tensor: A critical review. Surv Geophys, 35: 7-40

Cai J, Chen X, Xu X, Tang J, Wang L, Guo C, Han B, Dong Z. 2017. Rupture mechanism and seismotectonics of the $M_{\mathrm{s}} 6.5$ Ludian earthquake inferred from three-dimensional magnetotelluric imaging. Geophys Res Lett, 44: 1275-1285

Caldwell T G, Bibby H M, Brown C. 2004. The magnetotelluric phase tensor. Geophys J Int, 158: 457-469

Chave A D, Jones A G. 2012. The Magnetotelluric Method, Theory and Practice. Cambridge, U.K: Cambridge University Press

Chen M, Huang H, Yao H, van der Hilst R, Niu F. 2014. Low wave speed zones in the crust beneath SE Tibet revealed by ambient noise adjoint tomography. Geophys Res Lett, 41: 334-340

Chen Y, Xu Y, Xu T, Si S, Liang X, Tian X, Deng Y, Chen L, Wang P, Xu Y, Lan H, Xiao F, Li W, Zhang X, Yuan X, Badal J, Teng J. 2015. Magmatic underplating and crustal growth in the Emeishan Large Igneous Province, SW China, revealed by a passive seismic experiment. Earth Planet Sci Lett, 432: 103-114

Chen Z, Burchfiel B C, Liu Y, King R W, Royden L H, Tang W, Wang
E, Zhao J, Zhang X. 2000. Global positioning system measurements from eastern Tibet and their implications for India/Eurasia intercontinental deformation. J Geophys Res, 105: 16215-16227

Cheng Y, Tang J, Chen X, Dong Z, Wang L. 2019. Crustal structure and magma plumbing system beneath the Puer Basin, southwest China: Insights from three-dimensional magnetotelluric imaging. Tectonophysics, 763: 30-45

Clark M K, Royden L H. 2000. Topographic ooze: Building the eastern margin of Tibet by lower crustal flow. Geology, 28: 703-706

Comeau M J, Unsworth M J, Ticona F, Sunagua M. 2015. Magnetotelluric images of magma distribution beneath Volcán Uturuncu, Bolivia: Implications for magma dynamics. Geology, 43: 243-246

Deng Y, Zhang Z, Mooney W, Badal J, Fan W, Zhong Q. 2014. Mantle origin of the Emeishan large igneous province (South China) from the analysis of residual gravity anomalies. Lithos, 204: 4-13

Egbert G D, Kelbert A. 2012. Computational recipes for electromagnetic inverse problems. Geophys J Int, 189: 251-267

Egbert G D. 1997. Robust multiple-station magnetotelluric data processing. Geophys J Int, 130: 475-496

Farnetani C G, Richards M A, Ghiorso M S. 1996. Petrological models of magma evolution and deep crustal structure beneath hotspots and flood basalt provinces. Earth Planet Sci Lett, 143: 81-94

Foumier R O. 1991. The transition from hydrostatic to greater than hydrostatic fluid pressure in presently active continental hydrothermal systems in crystalline rock. Geophys Res Lett, 18: 955-958

Frost B R, Bucher K. 1994. Is water responsible for geophysical anomalies in the deep continental crust? A petrological perspective. Tectonophysics, 231: 293-309

Fu Y V, Gao Y, Li A, Li L, Chen A. 2017. Lithospheric structure of the southeastern margin of the Tibetan Plateau from Rayleigh wave tomography. J Geophys Res-Solid Earth, 122: 4631-4644

Gamble T D, Goubau W M, Clarke J. 1979. Magnetotellurics with a remote magnetic reference. Geophysics, 44: 53-68

Glover P W J, Hole M J, Pous J. 2000. A modified Archie's law for two conducting phases. Earth Planet Sci Lett, 180: 369-383

Gürer A, Bayrak M. 2007. Relation between electrical resistivity and earthquake generation in the crust of West Anatolia, Turkey. Tectonophysics, 445: 49-65

Han L, Peng Z, Johnson C W, Pollitz F F, Li L, Wang B, Wu J, Li Q, Wei H. 2017. Shallow microearthquakes near Chongqing, China triggered by the Rayleigh waves of the 2015 M7.8 Gorkha, Nepal earthquake. Earth Planet Sci Lett, 479: 231-240

Hashim L, Gaillard F, Champallier R, Le Breton N, Arbaret L, Scaillet B. 2013. Experimental assessment of the relationships between electrical resistivity, crustal melting and strain localization beneath 
the Himalayan-Tibetan Belt. Earth Planet Sci Lett, 373: 20-30

He B, Xu Y G, Chung S L, Xiao L, Wang Y. 2003. Sedimentary evidence for a rapid, kilometer-scale crustal doming prior to the eruption of the Emeishan flood basalts. Earth Planet Sci Lett, 213: 391-405

Hoffmann-Rothe A, Ritter O, Janssen C. 2004. Correlation of electrical conductivity and structural damage at a major strike-slip fault in northern Chile. J Geophys Res, 109: B10101

Hu J, Badal J, Yang H, Li G, Peng H. 2018. Comprehensive crustal structure and seismological evidence for lower crustal flow in the southeastern margin of Tibet revealed by receiver functions. Gondwana Res, 55: 42-59

Hu J, Yang H, Li G, Peng H. 2015. Seismic upper mantle discontinuities beneath Southeast Tibet and geodynamic implications. Gondwana Res, 28: 1032-1047

Huang J, Zhao D, Zheng S. 2002. Lithospheric structure and its relationship to seismic and volcanic activity in southwest China. J Geophys Res, 107: ESE 13-1-ESE 13-14

Huang Z, Wang L, Xu M, Zhao D. 2018. P wave anisotropic tomography of the SE Tibetan Plateau: Evidence for the crustal and upper-mantle deformations. J Geophys Res-Solid Earth, 123: $8957-8978$

Huang Z, Wang P, Xu M, Wang L, Ding Z, Wu Y, Xu M, Mi N, Yu D, Li H. 2015. Mantle structure and dynamics beneath SE Tibet revealed by new seismic images. Earth Planet Sci Lett, 411: 100111

Hyndman R D, Vanyan L L, Marquis G, Law L K. 1993. The origin of electrically conductive lower continental crust: Saline water or graphite? Phys Earth Planet Inter, 81: 325-345

Jones A G, Katsube T J, Schwann P. 1997. The longest conductivity anomaly in the world explained: Sulphides in fold hinges causing very high electrical anisotropy. J Geomagn Geoelec, 49: 1619-1629

Jones A G. 1993. Electromagnetic images of modern and ancient subduction zones. Tectonophysics, 219: 29-45

Kelbert A, Meqbel N, Egbert G D, Tandon K. 2014. ModEM: A modular system for inversion of electromagnetic geophysical data. Comput Geoscis, 66: 40-53

Kohlstedt D L, Evans B, Mackwell S J. 1995. Strength of the lithosphere: Constraints imposed by laboratory experiments. J Geophys Res, 100: 17587-17602

Lee C D, Vine F J, Ross R G. 1983. Electrical conductivity models for the continental crust based on laboratory measurements on highgrade metamorphic rocks. Geophys J Int, 72: 353-371

Lei J, Zhao D, Su Y. 2009. Insight into the origin of the Tengchong intraplate volcano and seismotectonics in southwest China from local and teleseismic data. J Geophys Res, 114: B05302
Lei J, Zhao D, Xu X, Xu Y G, Du M. 2019. Is there a big mantle wedge under eastern Tibet? Phys Earth Planet Inter, 292: 100-113

Leloup P H, Ricard Y, Battaglia J, Lacassin R. 1999. Shear heating in continental strike-slip shear zones: Model and field examples. Geophys J Int, 136: 19-40

Li D, Yu N, Li X, Wang E, Li R, Wang X. 2021. Magnetotelluric evidence of fluid-related seismicity beneath the Chuxiong Basin, SE Tibetan Plateau. Tectonophysics, 816: 229039

Li M, Zhang S, Wang F, Wu T, Qin W. 2016. Crustal and upper-mantle structure of the Southeastern Tibetan Plateau from joint analysis of surface wave dispersion and receiver functions. J Asian Earth Sci, 117: $52-63$

Li S, Unsworth M J, Booker J R, Wei W, Tan H, Jones A G. 2003. Partial melt or aqueous fluid in the mid-crust of Southern Tibet? Constraints from INDEPTH magnetotelluric data. Geophys J Int, 153: 289-304

Li W, Chen Y, Liang X, Xu Y G. 2021. Lateral seismic anisotropy variations records interaction between Tibetan mantle flow and plume-strengthened Yangtze Craton. J Geophys Res-Solid Earth, 126: e20841

Li X, Bai D, Ma X, Chen Y, Varentsov I M, Xue G, Xue S, Lozovsky I. 2019. Electrical resistivity structure of the Xiaojiang strike-slip fault system (SW China) and its tectonic implications. J Asian Earth Sci, 176: $57-67$

Li X, Ma X, Chen Y, Xue S, Varentsov I M, Bai D. 2020. A plumemodified lithospheric barrier to the southeastward flow of partially molten Tibetan crust inferred from magnetotelluric data. Earth Planet Sci Lett, 548: 116493

Li Y, Wu Q, Zhang R, Tian X, Zeng R. 2008. The crust and upper mantle structure beneath Yunnan from joint inversion of receiver functions and Rayleigh wave dispersion data. Phys Earth Planet Inter, 170: 134-146

Liu Q Y, van der Hilst R D, Li Y, Yao H J, Chen J H, Guo B, Qi S H, Wang J, Huang H, Li S C. 2014. Eastward expansion of the Tibetan Plateau by crustal flow and strain partitioning across faults. Nat Geosci, 7: 361-365

Molnar P, Tapponnier P. 1975. Cenozoic tectonics of Asia: Effects of a continental collision: Features of recent continental tectonics in Asia can be interpreted as results of the India-Eurasia collision. Science, 189: 419-426

Myer D, Constable S, Key K. 2013. Magnetotelluric evidence for layered mafic intrusions beneath the vøring and exmouth rifted margins. Phys Earth Planet Inter, 220: 1-10

Özaydın S, Selway K. 2020. MATE: An analysis tool for the interpretation of magnetotelluric models of the mantle. Geochem Geophys Geosyst, 21: e09126 
Pandey A P, Chadha R K. 2003. Surface loading and triggered earthquakes in the Koyna-Warna region, western India. Phys Earth Planet Inter, 139: 207-223

Parsons T, Ji C, Kirby E. 2008. Stress changes from the 2008 Wenchuan earthquake and increased hazard in the Sichuan basin. Nature, 454: 509-510

Peate I U, Bryan S E. 2008. Re-evaluating plume-induced uplift in the Emeishan large igneous province. Nat Geosci, 1: 625-629

Qiao L, Yao H, Lai Y C, Huang B S, Zhang P. 2018. Crustal structure of southwest China and northern Vietnam from ambient noise tomography: Implication for the large-scale material transport model in SE Tibet. Tectonics, 37: 1492-1506

Ritter O, Hoffmann-Rothe A, Bedrosian P A, Weckmann U, Haak V. 2005. Electrical conductivity images of active and fossil fault zones. Geol Soc Lond Spec Publ, 245: 165-186

Royden L H, Burchfiel B C, King R W, Wang E, Chen Z, Shen F, Liu Y. 1997. Surface deformation and lower crustal flow in eastern Tibet. Science, 276: 788-790

Royden L H, Burchfiel B C, van der Hilst R D. 2008. The geological evolution of the Tibetan Plateau. Science, 321: 1054-1058

Selway K. 2014. On the causes of electrical conductivity anomalies in tectonically stable lithosphere. Surv Geophys, 35: 219-257

Shen Z K, Lü J, Wang M, Bürgmann R. 2005. Contemporary crustal deformation around the southeast borderland of the Tibetan Plateau. J Geophys Res, 110: B11409

Stein R S. 2003. Earthquake conversations. Sci Am, 288: 72-79

Tapponnier P, Peltzer G, Le Dain A Y, Armijo R, Cobbold P. 1982. Propagating extrusion tectonics in Asia: New insights from simple experiments with plasticine. Geology, 10: 611-616

Tapponnier P, Zhiqin X, Roger F , Meyer B, Arnaud N, Wittlinger G, Jingsui Y. 2001. Oblique stepwise rise and growth of the Tibet Plateau. Science, 294: 1671-1677

Thompson A B, Connolly J A D. 1995. Melting of the continental crust: Some thermal and petrological constraints on anatexis in continental collision zones and other tectonic settings. J Geophys Res, 100: 15565-15579

Unsworth M, Bedrosian P A. 2004a. Electrical resistivity structure at the SAFOD site from magnetotelluric exploration. Geophys Res Lett, 31: L12S05

Unsworth M, Bedrosian P A. 2004b. On the geoelectric structure of major strike-slip faults and shear zones. Earth Planet Sp, 56: 11771184

Unsworth M J, Jones A G, Wei W, Marquis G, Gokarn S G, Spratt J E, Bedrosian P, Booker J, Leshou C, Clarke G, Shenghui L, Chanhong L, Ming D, Sheng J, Solon K, Handong T, Ledo J, Roberts B. 2005. Crustal rheology of the Himalaya and Southern Tibet inferred from magnetotelluric data. Nature, 438: 78-81

Unsworth M J, Rondenay S. 2013. Mapping the distribution of fluids in the crust and lithospheric mantle utilizing geophysical methods. In Harlov D, Austrheim H, eds. Metasomatism and the Chemical Transformation of Rock. Berlin Heidelberg: Springer-Verlag. 535598

Varentsov I M, Sokolova E Y, Martanus E, Nalivaiko K. 2003. System of electromagnetic field transfer operators for the BEAR array of simultaneous soundings: Methods and results. Izvest Phys Solid Earth, 39: 118-148

Wang M, Shen Z K. 2020. Present-day crustal deformation of continental China derivated from GPS and its tectonic implications. J Geophys Res-Solid Earth, 125: e18774

Wannamaker P E. 2000. Comment on "The petrologic case for a dry lower crust" by Bruce W. D. Yardley and John W. Valley. J Geophys Res, 105: 6057-6064

Wei W, Zhao D, Xu J. 2013. P-wave anisotropic tomography in Southeast Tibet: New insight into the lower crustal flow and seismotectonics. Phys Earth Planet Inter, 222: 47-57

Xu M, Huang Z, Wang L, Xu M, Zhang Y, Mi N, Yu D, Yuan X. 2020. Sharp lateral Moho variations across the SE Tibetan margin and their implications for plateau growth. J Geophys Res-Solid Earth, 125: e18117

Xu Y G, He B, Chung S L, Menzies M A, Frey F A. 2004. Geologic, geochemical, and geophysical consequences of plume involvement in the Emeishan flood-basalt province. Geology, 32: 917-920

Yang T, Liu F, Harmon N, Le K P, Gu S, Xue M. 2015. Lithospheric structure beneath Indochina Block from Rayleigh wave phase velocity tomography. Geophys J Int, 200: 1582-1595

Yang X, Keppler H, McCammon C, Ni H. 2012. Electrical conductivity of orthopyroxene and plagioclase in the lower crust. Contrib Mineral Petrol, 163: 33-48

Yao H, Beghein C, van der Hilst R D. 2008. Surface wave array tomography in SE Tibet from ambient seismic noise and two-station analysis-II. Crustal and upper-mantle structure. Geophys J Int, 173: $205-219$

Yao H. 2012. Lithospheric structure and deformation in SE Tibet revealed by ambient noise and earthquake surface wave tomography: Recent advances and perspectives. Earthq Sci, 25: 371-383

Yardley B W D, Valley J W. 1997. The petrologic case for a dry lower crust. J Geophys Res, 102: 12173-12185

Ye T, Huang Q, Chen X, Zhang H, Chen Y J, Zhao L, Zhang Y. 2018. Magma chamber and crustal channel flow structures in the Tengchong Volcano Area from 3-D MT inversion at the intracontinental block boundary southeast of the Tibetan Plateau. J Geophys Res-Solid Earth, 123: 11,112-11,126 
Yoshino T, Noritake F. 2011. Unstable graphite films on grain boundaries in crustal rocks. Earth Planet Sci Lett, 306: 186-192

Yu N, Unsworth M, Wang X, Li D, Wang E, Li R, Hu Y, Cai X. 2020. New insights into crustal and mantle flow beneath the Red River Fault zone and adjacent areas on the southern margin of the Tibetan Plateau revealed by a 3-D magnetotelluric study. J Geophys ResSolid Earth, 125: e19396

Zhang P Z, Shen Z, Wang M, Gan W, Bürgmann R, Molnar P, Wang Q, Niu Z, Sun J, Wu J, Sun H, You X. 2004. Continuous deformation of the Tibetan Plateau from global positioning system data. Geology,
32: $809-812$

Zhang P Z. 2013. A review on active tectonics and deep crustal processes of the Western Sichuan region, eastern margin of the Tibetan Plateau. Tectonophysics, 584: 7-22

Zhang S, Yu N, Wang E, Li D, Li R, Liu Y. 2021. The seismogenic structure and dynamic environment of Wulong $M_{\mathrm{S}} 5.0$ earthquake revealed by magnetotelluric imaging. Tectonophysics, 811: 228867

Zhao L F, Xie X B, He J K, Tian X, Yao Z X. 2013. Crustal flow pattern beneath the Tibetan Plateau constrained by regional $\mathrm{Lg}$-wave $\mathrm{Q}$ tomography. Earth Planet Sci Lett, 383: 113-122

(责任编委: 殷长春) 